
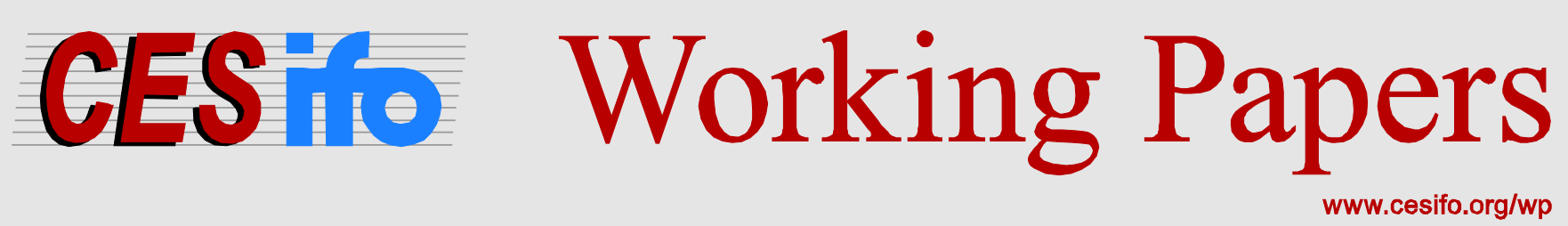

\title{
International Credit Flows and Pecuniary Externalities
}

\author{
Markus K. Brunnermeier \\ Yuliy Sannikov
}

\author{
CESIFO WORKING PAPER NO. 5170 \\ CATEgOry 7: Monetary POLICY AND InTERnAtional FinANCE \\ JANUARY 2015
}

ISSN 2364-1428

An electronic version of the paper may be downloaded

- from the SSRN website:

- from the RePEc website:

- from the CESifo website:

WWW.SSRN.com

Www.RePEc.org

www.CESifo-group.org/wp 


\title{
International Credit Flows and Pecuniary Externalities
}

\begin{abstract}
This paper develops a dynamic two-country neoclassical stochastic growth model with incomplete markets. Short-term credit flows can be excessive and reverse suddenly. The equilibrium outcome is constrained inefficient due to pecuniary externalities. First, an undercapitalized country borrows too much since each firm does not internalize that an increase in production capacity undermines their output price, worsening their terms of trade. From an ex-ante perspective each firm undermines the natural "terms of trade hedge." Second, sudden stops and fire sales lead to sharp price drops of illiquid capital. Capital controls or domestic macro-prudential measures that limit short-term borrowing can improve welfare.
\end{abstract}

JEL-Code: F330, F340, F360, F380, F410, G150.

Keywords: credit flows, capital flows, sudden stops, pecuniary externalities, hot money, Phoenix Miracle, terms of trade hedge.

\author{
Markus K. Brunnermeier \\ Department of Economics \\ Bendheim Center for Finance \\ Princeton University \\ USA - Princeton, NJ, 08544 \\ markus@princeton.edu
}

\author{
Yuliy Sannikov \\ Department of Economics \\ Bendheim Center for Finance \\ Princeton University \\ USA - Princeton, NJ, 08544 \\ sannikov@gmail.com
}

this version: December 19, 2014 / latest version:

https://www.dropbox.com/s/i43gtowevdqj0rl/_BrunnermeierSannikovInternational.pdf

We thank Mark Aguiar, Ozge Akinci, Gianluca Benigno, Zhiguo He, Sebastian Di Tella, Oleg Itskhoki, Anil Kashap, Guido Lorenzoni, Debbie Lucas, Ricardo Reis, Roberto Rigobon, Cédric Tille and participants at SED, NBER Summer Institute, IMF-Central Bank of Turkey conference, Barcelona Summer Forum, MFM conference, Yale University, World bank, Michigan State, UCL, Bank of England, London School of Economics, AEA Meetings in Philadelphia, Federal Reserve Board, NYU, the NBER conference on Lessons from the Financial Crisis in Boston, Boston College and at the Princeton Macro faculty lunch. We also thank Xiaoyang Sean Dong, Emil Verner, Christian Wolf, Yu Zhang and especially Zongbo Huang for excellent research assistance. 
For a long time the "Washington Consensus" held the view that free trade and full capital account liberalization are conducive to higher economic growth and welfare. A world in which goods and capital can flow freely was considered as the guiding "north star" and any incremental liberalization towards this ideal was considered as a step in the right direction. Recently, the IMF took on a more nuanced view, see Ostry et al. (2010). ${ }^{1}$ This more balanced view acknowledges that in a second best world, liberalizing only some markets might be harmful. Especially, the buildup of persistent capital flow imbalances in form of short-term debt, referred to as "hot money," increases the risk of financial instability. To avoid sudden reversals it might be desirable to "manage" capital flows. Capital controls should be part of the macroprudential tool kit.

We set up a quantifiable model that allows one to analyze capital account liberalization and capital controls. We identify circumstances under which short-term debt capital flows are excessive and can lead to inefficiencies and instabilities. To this end we develop a dynamic two-country, two-good stochastic growth model in continuous time with endogenous capital formation. International financial markets are imperfect but there are no international trade frictions. The two consumption goods and the single physical capital good can be traded freely. Like in the classic Ricardian trade model, each country has some (comparative) advantage in producing one good and hence should ideally specialize in producing that good. Our model shows that in a world with less than perfect risk sharing, (which can be justified by information problems and moral hazard considerations) although opening the capital account can boost overall economic growth, the resulting debt imbalances can lead to more volatility and therefore threaten financial stability. The key trade-off is between better allocation of physical capital and better risk sharing.

With an open international bond market the inflow of short-term hot money allows the poorer country to boost its production capacity, buying additional physical capital financed with debt from abroad. While this improves output levels, increased leverage makes the country vulnerable to additional shocks. Short-term debt acts as a palliative after a sequence of negative shocks, but the initial calm can be treacherous. With a bit of luck positive shocks follow and the strains on the global economy may never be noticed. However, if another bad shock arrives the country experiences a sudden stop of funding and conditions deteriorate quickly. Fear of future deterioration leads to fire sales, depressing the price of physical capital if it is technologically illiquid due to

\footnotetext{
${ }^{1}$ See also the policy recommendations in the report of the Committee on International Economic Policy and Reform (2012).
} 
adjustment costs or irreversibility of investment. The liquidity mismatch between low market and technological liquidity on the asset side and low funding liquidity due to short-term funding on the liability side is the driving force for this amplification. In addition, the country becomes vulnerable to "sunspot runs." A jump to a disaster equilibrium leads to a discrete drop in the price of capital, which abruptly erodes a country's wealth. If a total disaster can be avoided, countries can grow out of it relatively quickly, a phenomenon referred to by the literature as the Phoenix miracle. In short, better capital allocation funded with hot money comes at the cost of lower stability. Our framework allows a tight characterization of these endogenous volatility dynamics.

To answer the question whether free markets achieve the optimal balance in this trade off, i.e., whether private borrowing is excessive in a second best world, one has to conduct a welfare analysis. A closed capital account or domestic leverage restrictions limits a poor country's ability to build up its capital stock (e.g., after an adverse shock) and to produce goods for which it has a comparative advantage. This productive inefficiency limits economic growth, but comes with a favorable side effect: the price of its output good rises, i.e., the terms of trade improve. Symmetrically, after a positive shock the terms of trade worsen. The magnitude of this "terms of trade hedge" increases as the elasticity of substitution between the two outputs decreases. With an open capital account, debt financing enables each individual firm in the country to borrow and purchase more physical capital to produce more. However, by doing so, firms in the country jointly erode the terms of trade of their output good. Firms do not internalize this pecuniary externality, which leads to an overall welfare loss in the economy and globally. The competitive outcome is not constrained efficient. Moreover, increased leverage of each firm exposes all firms in this country to further risk. An additional adverse shock to indebted firms increases their concern about a sudden funding stop and they cut back their production scale by fire-selling their physical capital. While each firm in the country fully takes into account that it might have to fire-sell physical capital should further adverse shocks occur, they ignore that their initial debt financing as a group exacerbates this drop in value of physical capital. Sudden stops that lead to capital price drops due to self-fulfilling runs triggered by sunspots can also be seen through the lens of pecuniary externalities. In a complete markets setting capital allocation and risk sharing can be treated as two independent problems and these pecuniary externalities have no welfare effects, but in an incomplete markets setting they result in a constrained inefficient outcome. That is, a social planner that is limited to distort firms' actions within the same con- 
strained environment can increase overall welfare.

Like other macroprudential policies, capital controls are only welfare enhancing in certain circumstances. The terms of trade hedge is most powerful if both (i) consumers cannot easily substitute the output good with other goods, and (ii) other country is not skilled in producing this good. Hence, our results are most applicable for very specific output goods (oil or other natural resources come to mind.) Price movements mitigate the risk associated with a destruction of an oil facility or with the discovery of a new oil field. Bananas for Ecuador or computer hard drives for Thailand are a more specific example. In October 2011 a severe flood in Thailand impaired a quarter of the world's hard-drive production. The subsequent price surge helped the industry rebuild itself, see Fuller (2011).

Sudden stops due to self-fulfilling runs occur only if physical capital is sufficiently technologically illiquid and hence subject to large sudden price drops. These runs lead to sudden large wealth redistributions and destructions. Imposing capital controls that totally shut down international borrowing and lending might be "throwing the baby out with the bathwater" as one also forgoes significant capital allocation efficiency gains. Still, our framework shows that, under some circumstances, even a complete shutdown of short-term debt flows can be welfare-improving. Our framework thus even provides support for one of the most blunt macroprudential tools imaginable, and so by extension is also an endorsement of more nuanced macroprudential policy measures, for example maximum leverage ratios for domestic borrowers. A quantifiable model, like ours, allows policy makers to weigh various forces and fine-tune the policy measures.

One such important factor is the size of a country's (comparative) advantage in producing a specific good. Noticing that countries can affect this advantage, e.g., through R\&D spending, points to another inefficiency. Improving productivity for advantaged products fosters further specialization. In contrast, when a country improves productivity for disadvantaged goods they improve their terms of trade at the expense of the other country, Samuelson (2004). As both countries try to imitate each other's technology, the resources diverted from other productive activities are a pure welfare loss. Our analysis adds to this discussion by pointing out that such government activity destroys the terms of trade hedge. Overall, a global social planner would foster R\&D spending that leads to more specialization rather than to catching up policies, since the resulting output price movements provide natural insurance.

Finally, the paper also shows that at times of severe wealth inequality across countries an unanticipated redistribution, e.g., by diluting creditors' debt claims or straight 
debt relief, can be Pareto improving. Each individual creditor would be reluctant to sign on to this scheme, even though as a group all creditors are better off. To understand why, note that creditors are also consumers in our setting. Consumers benefit if goods produced in countries that have the comparative advantage of producing them.

Related Literature. Relative to the existing literature our framework makes several contributions. The model can be seen as a two-country two-good version of Brunnermeier and Sannikov $(2014,2011)$, which build in turn on the seminal contributions of Bernanke, Gertler and Gilchrist (1999) and Kiyotaki and Moore (1997). Inefficiencies can arise due to pecuniary externalities, which can be due to exogenous credit constraints or an incomplete markets.

Pecuniary fire sale externalities are the subject of extensive study in finance and international economics. In most models inefficiencies arise because the price move tightens an exogenously imposed collateral constraint, see e.g. Caballero and Krishnamurthy (2004) or Korinek (2011). In Aoki, Benigno and Kiyotaki (2009) collateral debt limits are lower for international lending than for domestic lending arrangements. ${ }^{2}$ In Bianchi (2011), Bianchi and Mendoza (2012) and Mendoza (2010), this constraint binds occasionally, potentially leading to sudden stops. Jeanne and Korinek (2011) proposes a Pigouvian tax to correct for the externality. Benigno et al. (2014) study the interaction between ex-ante and ex-post policy interventions. In contrast, we do not impose any exogenous debt constraint. In our setting a sudden decline in debt arises endogenously due to the incomplete markets setting, as firms are limited in issuing equity claims.

Our paper falls in a second strand of literature in which pecuniary externalities lead to constrained inefficient outcomes in a multi-good setting due to incomplete markets-that is, no exogenous credit constraint is imposed. It follows the general equilibrium literature (Stiglitz (1982), Geanakoplos and Polemarchakis (1986)). Newbery and Stiglitz (1984)'s incomplete markets setting shares the feature that free trade destroys the automatic hedge that price movements provide. However, their paper is about free trade of goods rather than open capital account. Our analysis also highlights that partially completing the market can lead to inferior outcomes, a result that was shown in the GE literature by Hart (1975). More recently, He and Kondor (2013) consider two inputs, cash and capital and show that pecuniary externalities can lead to overinvestment booms and too little investment in recessions. Phelan (2013)'s

\footnotetext{
${ }^{2}$ In Maggiori (2013) countries differ in their financial developments rather than in producing different goods.
} 
continuous time model considers a two-good economy in which banks owned by households play a central role.

Our framework is general enough that it can have quantitative implications after some calibration. In this sense our model is closer to the canonical international RBC model with capital formation as in Backus, Kehoe and Kydland (1994). Similar to us, Pavlova and Rigobon (2007) develop a two-country, two-good continuous-time model with international financial and trade linkages. Unlike Backus, Kehoe and Kydland (1994) or Pavlova and Rigobon (2007), however, we consider an incomplete market setting. Hence, we cannot use the standard macroeconomic approach of solving the planner's problem and then decentralizing the (global) economy. Heathcote and Perri (2014) follow our incomplete markets setting, but have a different shock structure and goods home bias. Corsetti, Dedola and Leduc (2008) resolve the Backus-Smith puzzle, i.e., the negative correlation between the real exchnage rate and relative consumption, by employing an incomplete market structure with appropriate productivity shocks. Coeurdacier, Rey and Winant (2013) also analyze the trade-off between efficient capital allocation and improved risk sharing. Instead of analyzing pecuniary externalities, they focus on precautionary savings conducted primarily by emerging markets. Like Obstfeld and Rogoff (1995)'s New Keynesian framework, we focus on short-term international debt. Benigno (2009) evaluates the welfare costs of incomplete markets and the gains of deviating from a policy of price stability in the New Keynesian setting. These papers are restricted by the log-linearization technique around the steady state; our analysis includes crisis events far away from the steady-state.

Costinot, Lorenzoni and Werning (2014) derive the optimal capital flow tax for a country that tries to manipulate the terms of trade in order to extract monopoly rents from the other countries, an insight that can be traced back to the debate between Keynes (1929) and Ohlin (1929). Our analysis is focused on risk and capital controls that improve the "terms of trade hedge" can benefit both countries. The terms of trade hedge argument was anticipated in Helpman and Razin (1978) and later formally introduced in the seminal paper by Cole and Obstfeld (1991). We gain additional insights by varying the elasticity of substitution across both goods. In addition, we show that capital irreversibility requires an even greater hedge than provided by a Cobb-Douglas elasticity of substitution. Like our paper, Heathcote and Perri (2013) also allows for endogenous capital formation. The focus of their analysis is to replicate empirical patterns identified in the international business cycles literature. Since all the debt financing is short-term, our analysis also speaks to hot money in international capital flow and the fear of losing control of monetary policy by the 
monetary authority. For a detailed survey on international finance crises including sudden stops, see Lorenzoni (2014). In Gabaix and Maggiori (2014) the financial markets are fragmented and the exchange rate is driven by the net worth of the financial sector.

Another strand of papers study the benefits of capital controls in the presence of price and wage rigidities. For example, Farhi and Werning (2012) argue that nominal rigidities can lead to inefficiencies that justify capital controls. If in addition currencies are pegged to each other, Schmitt-Grohé and Uribe $(2012,2013)$ show that free capital movements can cause a negative externality that contributes to higher unemployment. Farhi and Werning (2013) highlight the benefits of contingent wealth transfers within a currency union.

Empirical evidence about the effect of capital account liberalizations are mixed. See, e.g. Obstfeld and Taylor (2004) or Magud, Reinhart and Rogoff (2011). There are several examples where capital account liberalizations spurred growth but also others where they led to subsequent crises. Prominent examples are the Scandinavian crisis in the early 1990s and the South East Asia crisis in the late 1990s. The terms "sudden stop" and "Phoenix miracle" were coined and empirically documented in Calvo (1998) and Calvo, Izquierdo and Talvi (2006).

\section{The Model}

In this section we develop a simple baseline model of a global economy that is populated by agents who live in two different countries, $A$ and $B$. Both types of agents have the same preferences and can own capital. They can also both produce the two consumption goods $a$ and $b$. Like in the classical Ricardian trade model agents in country $A$ have a comparative advantage in producing product $a$, while agents in country $B$ are better at producing good $b$. There are no trade barriers for the two output goods $a$ and $b$ as well as for the input good, physical capital. We focus on frictions in the international finance markets. In particular we contrast a global economy in which capital account is closed with a world in which the current account is open for short-term debt instruments. We also derive the benchmark outcome for the case when all contingent claims can be traded. 


\section{A Model Setup}

Technology. Capital can be used to produce goods $a$ or $b$, which can be combined to produce the aggregate good. The aggregate good can be consumed, or used for investment to produce new capital.

When quantities $y^{a}$ and $y^{b}$ of goods $a$ ("apples") and $b$ ("bananas") are combined, they make a total quantity

$$
y=\left[\frac{1}{2}\left(y^{a}\right)^{\frac{s-1}{s}}+\frac{1}{2}\left(y^{b}\right)^{\frac{s-1}{s}}\right]^{\frac{s}{s-1}},
$$

of the aggregate good. Note that both goods are equally weighted, since we abstract from any home bias for local goods. For $s=\infty$ both goods are perfect substitutes, for $s=0$ there is no substitutability á la Leontieff, while for $s=1$ the substitutabililty corresponds to that of a Cobb-Douglas utility function. The index/aggregate good serves as numeraire and its price is normalized to one.

Agents in country A are better at producing good $a$, while agents in country $B$ are better at producing $b$. From $k_{t}$ units of capital, an agent in country A can produce good $a$ at rate $\bar{a} k_{t}$ and good $b$ at rate of only $\underline{a} k_{t}$, where $\bar{a}>\underline{a} \geq 0 .{ }^{3}$ Symmetrically, an individual in country B can produce good $b$ at rate $\bar{a} k_{t}$ and good $a$ at rate only $\underline{a} k_{t}$.

We denote the aggregate amount of world capital at time $t \in[0, \infty)$ by $K_{t}$. Denote the fraction of world capital used by agents in country $A$ to produce good $a$ by $\psi_{t}^{A a}$, the fraction used by agents in country $B$ to produce good $b$ by $\psi_{t}^{B b}$, etc., so that

$$
\psi_{t}^{A a}+\psi_{t}^{A b}+\psi_{t}^{B a}+\psi_{t}^{B b}=1
$$

Then the total world supply of goods $a$ and $b$ is given by

$$
Y_{t}^{a}=\left(\bar{a} \psi_{t}^{A a}+\underline{a} \psi_{t}^{B a}\right) K_{t} \quad \text { and } \quad Y_{t}^{b}=\left(\bar{a} \psi_{t}^{B b}+\underline{a} \psi_{t}^{A b}\right) K_{t}
$$

respectively. The total supply of the aggregate good is, naturally,

$$
Y_{t}=\left[\frac{1}{2}\left(Y_{t}^{a}\right)^{\frac{s-1}{s}}+\frac{1}{2}\left(Y_{t}^{b}\right)^{\frac{s-1}{s}}\right]^{\frac{s}{s-1}}
$$

\footnotetext{
${ }^{3}$ If $\underline{a}=0$, then country A will not use capital to produce good $b$, because it is a strictly (weakly if there is no country B) dominant strategy to produce good $a$.
} 
and the prices of goods $a$ and $b$ in terms of the numeraire/aggregate good are

$$
P_{t}^{a}=\frac{1}{2}\left(\frac{Y_{t}}{Y_{t}^{a}}\right)^{1 / s} \quad \text { and } \quad P_{t}^{b}=\frac{1}{2}\left(\frac{Y_{t}}{Y_{t}^{b}}\right)^{1 / s} .
$$

There is a single type of physical capital. Capital is subject to shocks, which depend on the country $I=A, B$ in which the capital is employed. Also, new capital can be built through internal investment by using the aggregate good. Overall, capital employed in country $I$ evolves according to

$$
\frac{d k_{t}}{k_{t}}=\left(\Phi\left(\iota_{t}\right)-\delta\right) d t+\sigma^{I} d Z_{t}^{I},
$$

where $\iota_{t}$ is the investment rate of the aggregate good per unit of capital (i.e., $\iota_{t} k_{t}$ is the total investment rate). Function $\Phi$, which satisfies $\Phi(0)=0, \Phi^{\prime}(0)=1, \Phi^{\prime}(\cdot)>0$, and $\Phi^{\prime \prime}(\cdot)<0$, represents a standard investment technology with adjustment costs. In the absence of investment, capital depreciates at rate $\delta$. The concavity of $\Phi(\iota)$ represents technological illiquidity, i.e., the adjustment cost due to converting output to new capital and vice versa. The two Brownian motions $d Z_{t}^{A}, d Z_{t}^{B}$ are exogenous and independent. They are country specific. Examples of such shocks are the discovery of new resources or natural catastrophes like earthquakes and tsunamis. If one interprets $k_{t}$ as being measured in efficiency units instead of physical number of machines, then the shocks also capture innovations in productivity.

Preferences. All agents in the world have identical risk and intertemporal preferences represented by the expected utility function

$$
\mathbb{E}_{0}\left[\int_{0}^{\infty} e^{-r t} \frac{c_{t}^{1-\gamma}}{1-\gamma} d t\right]
$$

where $c_{t}$ is the individual consumption of the aggregate good.

Markets for Physical Capital and the Risk-Free Bond. All agents can trade physical capital in a fully liquid international market. We denote the equilibrium market price of capital per unit by $q_{t}$ (measured in the aggregate good). That is, capital $k_{t}$ is worth 
$q_{t} k_{t}$. For now, we postulate the law of motion $q_{t}$ to be of the form

$$
\frac{d q_{t}}{q_{t}}=\mu_{t}^{q} d t+\sigma_{t}^{q A} d Z_{t}^{A}+\sigma_{t}^{q B} d Z_{t}^{B}
$$

with undertermined (time-dependent) drift and volatility terms. Our conjecture will be verified later.

Absent capital controls and macroprudential regulation there is also an international market for the risk-free bond, which is in zero net supply. Agents can go long (lend) or short (borrow) in the risk-free asset. The return on the risk-free asset is denoted by $\frac{d r_{t}^{F}}{d t}$. In equilibrium both $q_{t}$ and $d r_{t}^{F}$ are determined endogenously. ${ }^{4}$

Returns from Holding Physical Capital. The return from capital depends on the identity of the agent holding it and the good that it is used to produce. The capital gains from capital are given by $d\left(q_{t} k_{t}\right) /\left(q_{t} k_{t}\right)$, where $k_{t}$ and $q_{t}$ evolve as (5) and (6). The dividend yield from capital - after reinvesting output at a rate $\iota_{t}$ - is given by $\left(\bar{a} P_{t}^{i}-\iota_{t}\right) / q_{t}$ when it is used productively to produce good $i=a, b$, and by $\left(\underline{a} P_{t}^{i}-\right.$ $\left.\iota_{t}\right) / q_{t}$ otherwise. Therefore, when an agent of type $A$ uses capital to produce good $a$, he earns the return of

$$
d r_{t}^{A a}=\left(\frac{\bar{a} P_{t}^{a}-\iota_{t}}{q_{t}}+\mu_{t}^{q}+\Phi\left(\iota_{t}\right)-\delta+\sigma^{A} \sigma_{t}^{q A}\right) d t+\left(\sigma^{A}+\sigma_{t}^{q A}\right) d Z_{t}^{A}+\sigma_{t}^{q B} d Z_{t}^{B},
$$

where we used Ito's lemma to compute the capital gains portion of the return, $d\left(q_{t} k_{t}\right) /\left(q_{t} k_{t}\right)$. The Ito-term $\sigma^{A} \sigma_{t}^{q A}$ reflects the covariance between the exogenous volatility of capital stock in country $A$ and the endogenous risk price exposure. When agent $A$ uses capital to produce good $b$, he earns

$$
d r_{t}^{A b}=\left(\frac{\underline{a} P_{t}^{b}-\iota_{t}}{q_{t}}+\mu_{t}^{q}+\Phi\left(\iota_{t}\right)-\delta+\sigma^{A} \sigma_{t}^{q A}\right) d t+\left(\sigma^{A}+\sigma_{t}^{q A}\right) d Z_{t}^{A}+\sigma_{t}^{q B} d Z_{t}^{B} .
$$

Similar equations hold for agents B. The optimal investment rate, which maximizes returns, is always given by the first-order condition

$$
\Phi^{\prime}(\iota)=1 / q_{t}
$$

\footnotetext{
${ }^{4}$ Note that we use the notation $\frac{d r_{t}^{F}}{d t}$ for the risk-free rate in order to allow for potential nondifferentiabilities.
} 
Financial Frictions, Incomplete Markets and Equity Home Bias. There are financial frictions in this economy. We assume that, absent capital controls and macroprudential regulations, agents can borrow through risk-free debt to buy capital, but cannot internationally share risk of the capital they employ by issuing equity or through other means. Thus, international markets are incomplete. ${ }^{5}$ Home bias in investors' equity holdings is very well documented, see Lewis (1999). We simply assume that investors do not hold any foreign capital risk. Our results are robust to a more general setting with partial risk sharing, as long as some equity home bias remains. Agency problems and asymmetric information problems are an alternative way to micro-found limited risk sharing. 6

Each agent chooses his consumption rate, as well as the allocation of wealth to capital used to produce each good and to the risk-free asset. When agent $I=A, B$ consumes at rate $c_{t}^{I}>0$ and chooses portfolio with weights $\left(x_{t}^{a}, x_{t}^{b}, 1-x_{t}^{a}-x_{t}^{b}\right)$, his net worth $n_{t}$ evolves according to

$$
\frac{d n_{t}^{I}}{n_{t}^{I}}=x_{t}^{a} d r_{t}^{I a}+x_{t}^{b} d r_{t}^{I b}+\left(1-x_{t}^{a}-x_{t}^{b}\right) d r_{t}^{F}-\frac{c_{t}^{I}}{n_{t}^{I}} d t
$$

Equation (8) (together with the solvency constraint $n_{t} \geq 0$ ) can be thought of as the agent's budget constraint. Portfolio weights $x_{t}^{a}$ and $x_{t}^{b}$ must be nonnegative for all agents.

Definition. For any initial allocation of wealth, an equilibrium is a map from histories of shocks $\left\{Z_{s}^{A}, Z_{s}^{B}, s \in[0, t]\right\}$ to the allocation of capital $\left(\psi_{t}^{A a}, \psi_{t}^{A b}, \psi_{t}^{B a}, \psi_{t}^{B b}\right)$ and the aggregate consumption good $\left(C_{t}^{A}, C_{t}^{B}\right)$ as well as prices $q_{t}$ and $d r_{t}^{F}$ such that

1. all agents solve their optimal consumption and portfolio choice problems, subject to the budget constraints and

2. all markets clear, i.e. ${ }^{7}$

$$
\psi_{t}^{A a}+\psi_{t}^{A b}+\psi_{t}^{B a}+\psi_{t}^{B b}=1 \quad \text { and } \quad C_{t}^{A}+C_{t}^{B}=Y_{t}-\iota_{t} K_{t}
$$

where $Y_{t}$ is given by (3).

\footnotetext{
${ }^{5}$ Domestic markets are complete but international markets are incomplete, which is consistent with the observed equity home bias.

${ }^{6}$ See Jensen and Meckling (1976), Bolton and Scharfstein (1990), and DeMarzo and Sannikov (2006).

${ }^{7}$ If the markets for capital and aggregate output clear, then the market for the risk-free asset clears automatically by the Walras' Law.
} 
We denote the net worth of all agents in country $A$ at time $t$ by $N_{t}$ and the net worth share (wealth share) of agents of country $A$, by $\eta_{t} \equiv N_{t} /\left(q_{t} K_{t}\right)$. Then the portfolio weights of representative agent $A$ are given by

$$
\left(\frac{\psi_{t}^{A a}}{\eta_{t}}, \frac{\psi_{t}^{A b}}{\eta_{t}}, 1-\frac{\psi_{t}^{A a}+\psi_{t}^{A b}}{\eta_{t}}\right)
$$

and consumption rate by $\zeta_{t}^{A}=C_{t}^{A} / N_{t}$. Likewise, for agents $B$, these are given by

$$
\left(\frac{\psi_{t}^{B a}}{1-\eta_{t}}, \frac{\psi_{t}^{B b}}{1-\eta_{t}}, 1-\frac{\psi_{t}^{B a}+\psi_{t}^{B b}}{1-\eta_{t}}\right) \quad \text { and } \quad \zeta_{t}^{B}=\frac{C_{t}^{B}}{q_{t} K_{t}-N_{t}} .
$$

Asset-pricing equations. Here, we take a technical detour to summarize equations that price available assets from the agent's consumption processes. Let us postulate that consumption $C_{t}^{A}$ of agents $A$ follows

$$
\frac{d C_{t}^{A}}{C_{t}^{A}}=\mu_{t}^{C^{A}} d t+\sigma_{t}^{C^{A} A} d Z_{t}^{A}+\sigma_{t}^{C^{A} B} d Z_{t}^{B}
$$

The stochastic discount factor $\theta_{t}^{A}=e^{-r t}\left(C_{t}^{A} / C_{0}^{A}\right)^{-\gamma}$ of agents $\mathrm{A}$ depends on their discounted marginal utility. By Ito's lemma

$$
\frac{d \theta_{t}^{A}}{\theta_{t}^{A}}=\underbrace{\mu_{t}^{\theta^{A}} d t}_{-d r_{t}^{F}}-\gamma\left(\sigma_{t}^{C^{A} A} d Z_{t}^{A}+\sigma_{t}^{C^{A} B} d Z_{t}^{B}\right)
$$

The return of any asset available to agents $A$ has to satisfy the following property: if wealth $\epsilon_{t}$ is invested in asset $X$, so that $d \epsilon_{t} / \epsilon_{t}=d r_{t}^{X}$, then $\theta_{t}^{A} \epsilon_{t}$ must be a martingale if the portfolio allocation to $X$ is positive (and a supermartingale if the portfolio allocation is zero). In other words, the drift of $\theta_{t}^{A} \epsilon_{t}$ must be zero (negative). For the risk free asset it follows directly that

$$
\frac{d r_{t}^{F}}{d t}=-\mu_{t}^{\theta^{A}}=r+\gamma \mu_{t}^{C^{A}}-\frac{\gamma(\gamma+1)}{2}\left(\left(\sigma_{t}^{C^{A} A}\right)^{2}+\left(\sigma_{t}^{C^{A} B}\right)^{2}\right) .
$$

The pricing condition for capital used to produce output $a$ is

$$
\frac{\mathbb{E}\left[d r_{t}^{A a}\right]}{d t}+\mu_{t}^{\theta^{A}}=\underbrace{\gamma \sigma_{t}^{C^{A} A}\left(\sigma^{A}+\sigma_{t}^{q A}\right)+\gamma \sigma_{t}^{C^{A} B} \sigma_{t}^{q B}}_{-\operatorname{Cov}\left[d r_{t}^{A a}, d \theta_{t}^{A} / \theta_{t}^{A}\right]} .
$$


The negative of the under-braced Ito terms reflect the risk premium, i.e., the required expected excess return in equilibrium. Likewise, for capital used to produce good $b$,

$$
\frac{\mathbb{E}\left[d r_{t}^{A b}\right]}{d t}+\mu_{t}^{\theta^{A}} \leq \underbrace{\gamma \sigma_{t}^{C^{A} A}\left(\sigma^{A}+\sigma_{t}^{q A}\right)+\gamma \sigma_{t}^{C^{A} B} \sigma_{t}^{q B}}_{-\operatorname{Cov}\left[d r_{t}^{A b}, d \theta_{t}^{A} / \theta_{t}^{A}\right]} .
$$

with equality if agents A devote a positive amount of capital to produce good $b$, i.e. $\psi_{t}^{A b}>0$. Similar equations also hold for agents B.

\section{B First-best Benchmark}

In the economy without frictions and complete markets, full specialization realizes. Agents $A$ specialize in producing only output good $a$ and agents $B$ only produce output $\operatorname{good} b$.

For simplicity, assume a symmetric economy, in which $\sigma^{A}=\sigma^{B}=\sigma$. Then, given the efficient allocation of capital to the production of the two goods, $\psi_{t}^{A a}=\psi_{t}^{B b}=1 / 2$ and $\psi_{t}^{A b}=\psi_{t}^{B a}=0$, the total aggregate output is

$$
Y_{t}=\frac{\bar{a} K_{t}}{2}
$$

A social planner that assigns Pareto weights $(\lambda, 1-\lambda)$ must divide the consumption stream according to the shares

$$
\left(\frac{\lambda^{1 / \gamma}}{\lambda^{1 / \gamma}+(1-\lambda)^{1 / \gamma}}, \frac{(1-\lambda)^{1 / \gamma}}{\lambda^{1 / \gamma}+(1-\lambda)^{1 / \gamma}}\right) .
$$

With complete markets agents fully share the risks $d Z_{t}^{A}$ and $d Z_{t}^{B}$. That is, any redistributive shock is offset, but the aggregate shocks to the global capital stock $K_{t}$ have to be borne. The price of capital and the risk-free rate are given by the following proposition.

Proposition 1 With complete markets, the market outcome leads to the first-best allocation with full specialization, $\psi_{t}^{A a}=\psi_{t}^{B b}=1 / 2$. The risk-free rate $\frac{d r_{t}^{F}}{d t}$ and the price of capital are time-invariant and given by

$$
\frac{d r^{F}}{d t}=r+\gamma(\Phi(\iota)-\delta)-\frac{\gamma(\gamma+1) \sigma^{2}}{4} \text { and } q=\frac{\bar{a} / 2-\iota}{d r^{F} / d t+\gamma \sigma^{2} / 2-(\Phi(\iota)-\delta)} .
$$


The time-invariant wealth shares $(\eta, 1-\eta)$ are also the consumption shares. The corresponding Pareto weights of the centralized economy can be found from (14).

Proof. See Appendix A.

The first-best benchmark economy which emerges in a setting with complete markets is particularly simple. The size of the economy essentially scales up or down depending on the total shock $d Z_{t}^{A}+d Z_{t}^{B}$. All relative quantities, like wealth shares, stay constant and so do prices. The risk-free rate $d r^{F} / d t$ is determined by the timepreference rate $r$, the expected growth rate of capital (and the economy) and aggregate risk. As overall aggregate risk increases, the risk-free asset becomes relatively more attractive and hence the risk-free rate falls. The price $q_{t}$ of physical capital is given by the Gordon growth formula, where the denominator is the required return on capital minus the growth rate of capital.

\section{Open Capital Account for Debt}

In this section, we analyze the equilibrium in an economy in which agents in both countries can borrow through risk-free debt. Markets are not complete since agents cannot issue equity claims to foreigners (equity home bias.) In the next section we contrast these findings with an economy in which the capital account is closed.

Technically, the equilibrium with debt is characterized by the asset pricing equations (12), (13) and (11) for agents of type A, together with analogous equations for agents of type B, the market-clearing conditions (9) and equations (2), (3) and (4) that determine output and prices. We use these equations, together with the law of motion of $\eta_{t}$ given by Proposition 2, to solve for the equilibrium quantities as functions of the wealth allocation, summarized by $\eta_{t}$.

First let us define the volatility coefficient. With portfolio weights $\psi_{t}^{A a} / \eta_{t}$ and $\psi_{t}^{A b} / \eta_{t}$ on the two technologies, the law of motion of the net worth of agents in country $A$ is

$$
\begin{aligned}
\frac{d N_{t}}{N_{t}} & =\frac{\psi_{t}^{A a}+\psi_{t}^{A b}}{\eta_{t}} \gamma\left(\left(\sigma^{A}+\sigma_{t}^{q A}\right) \sigma_{t}^{C^{A} A}+\sigma_{t}^{q B} \sigma_{t}^{C A B}\right) d t+d r_{t}^{F}-\frac{C_{t}^{A}}{N_{t}} d t \\
& +\underbrace{\frac{\psi_{t}^{A a}+\psi_{t}^{A b}}{\eta_{t}}\left(\sigma^{A}+\sigma_{t}^{q A}\right)}_{\sigma_{t}^{N A}} d Z_{t}^{A}+\underbrace{\frac{\psi_{t}^{A a}+\psi_{t}^{A b}}{\eta_{t}} \sigma_{t}^{q B}}_{\sigma_{t}^{N B}} d Z_{t}^{B}
\end{aligned}
$$


The process of net worth of agents in country $B$ can be derived in a similar way.

Proposition 2 characterizes the equilibrium including the evolution of wealth share $\eta$. The two shocks $d Z_{t}^{A}$ and $d Z_{t}^{B}$ affect both (i) the global capital stock $K_{t}$ as well as (ii) the relative wealth shares $\eta_{t}$. In other words, shocks have redistributive consequences. This allows us to provide a different interpretation of the shock structure. Our framework also captures redistributive shocks, like losing a large law suit (think of Samsung losing a large law suit against Apple). The initial direct redistributional impact leads agents to reoptimize, e.g., sell capital after losing a law suit, which can amplify into further redistributional effects. Our analysis captures the joint effect, the initial impact plus the endogenous redistributional responses.

Proposition 2 The state space can be divided into three regions. In the middle region, $\eta \in$ $\left[\eta^{a}, \eta^{b}\right]$ all agents engage only in their most productive technology (full specialization), i.e. $\left(\psi_{t}^{A b}=\psi_{t}^{B a}=0\right)$. In the left region $\left[0, \eta^{a}\right), \psi_{t}^{B a}>0$ and the right region $\left(\eta^{b}, 1\right], \psi_{t}^{A b}>0$. When $\psi^{A b}=0$ (left and middle region), $\eta_{t}$ follows

$$
\begin{gathered}
\frac{d \eta_{t}}{\eta_{t}}=\frac{1-\eta_{t}}{\eta_{t}} \psi_{t}^{A a} \gamma\left[\left(\sigma^{A}+\sigma_{t}^{q A}\right) \sigma_{t}^{C^{A} A}+\sigma_{t}^{q B} \sigma_{t}^{C^{A} B}\right] d t \\
-\left(1-\psi_{t}^{A a}\right) \gamma\left[\sigma_{t}^{q A} \sigma_{t}^{C^{B} A}+\left(\sigma^{B}+\sigma_{t}^{q B}\right) \sigma_{t}^{C^{B} B}\right] d t+\underbrace{\frac{Y_{t}-l_{t} K_{t}}{q_{t} K_{t}} d t-\frac{C_{t}^{A}}{N_{t}} d t}_{=0 \text { if } \gamma=1} \\
\left.-\left[\psi_{t}^{A a} \sigma^{A}+\sigma_{t}^{q A}\right] \sigma_{t}^{\eta A} d t-\left[\sigma_{t}^{q B}+\left(1-\psi_{t}^{A a}\right) \sigma^{B}\right)\right] \sigma_{t}^{\eta B} d t+ \\
\underbrace{\left[\frac{\psi_{t}^{A a}-\eta_{t}}{\eta_{t}} \sigma_{t}^{q A}+\frac{1-\eta_{t}}{\eta_{t}} \psi_{t}^{A a} \sigma^{A A}\right]}_{\sigma_{t}^{\eta A}} d Z_{t}^{A}+\underbrace{\left[\frac{\psi_{t}^{A a}-\eta_{t}}{\eta_{t}} \sigma_{t}^{q B}-\left(1-\psi_{t}^{A a}\right) \sigma^{B}\right]}_{\sigma_{t}^{\eta B}} d Z_{t}^{B},
\end{gathered}
$$

and in the right region $\eta_{t}$ follows a symmetric equation.

In terms of asset pricing, in all three regions

$$
\begin{gathered}
\frac{\bar{a}\left(P_{t}^{a}-P_{t}^{b}\right)}{q_{t}}+\sigma^{A} \sigma_{t}^{q A}-\sigma^{B} \sigma_{t}^{q B}= \\
\gamma\left(\left(\sigma^{A}+\sigma_{t}^{q A}\right) \sigma_{t}^{C^{A} A}+\sigma_{t}^{q B} \sigma_{t}^{C^{A} B}-\sigma_{t}^{q A} \sigma_{t}^{C^{B} A}-\left(\sigma^{B}+\sigma_{t}^{q B}\right) \sigma_{t}^{C^{B} B}\right) .
\end{gathered}
$$

In addition,

$$
\underline{a} / \bar{a} \leq \frac{P^{b}}{P^{a}} \leq \bar{a} / \underline{a}
$$


In the left region the first inequality becomes equality, and right, the second.

If $\gamma=1$, then the price of capital $q_{t}$ satisfies

$$
\left[\frac{1}{2}\left(\bar{a} \psi_{t}^{A a}+\underline{a} \psi_{t}^{B a}\right)^{\frac{s-1}{s}}+\frac{1}{2}\left(\bar{a} \psi_{t}^{B b}+\underline{a} \psi_{t}^{A b}\right)^{\frac{s-1}{s}}\right]^{\frac{s}{s-1}}-\iota(q(\eta))=r q(\eta) .
$$

Proof. See Appendix B.

Note that all equations hold for any risk aversion coefficient $\gamma$, while the market clearing condition takes the simple form (19) only for log utility, i.e. when $\gamma=1$.

For the left and middle regions, we can use Equation (16) to evaluate the volatilities of $\eta$ and $q$ from $\psi_{t}^{A a}$ and the values of $q_{t}\left(\eta_{t}\right)$ and $q_{t}^{\prime}\left(\eta_{t}\right)$. Indeed, using Ito's lemma,

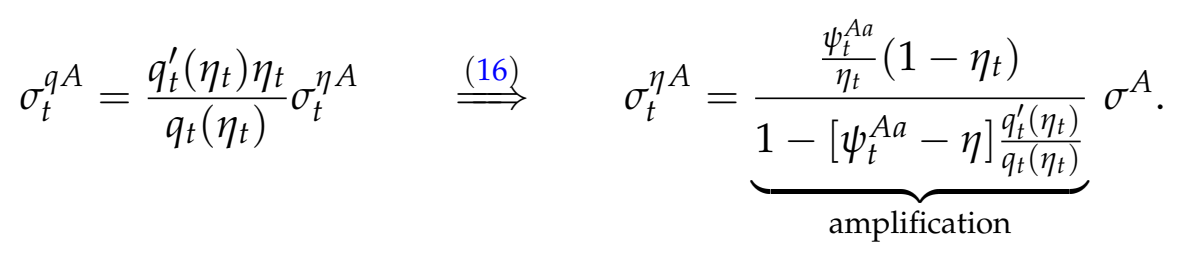

The factor in front of $\sigma^{A}$ highlights the amplification. The numerator captures the amplification effect due to the leverage effect. Recall that $\psi_{t}^{A a} / \eta_{t}$ is $A^{\prime}$ s leverage. The denominator captures the loss spiral. If the price of capital is more sensitive, i.e., $q^{\prime}(\eta)$ is larger, additional losses arise which amplify the endogenous risk even further. For constant $q_{t}$, i.e. $q_{t}^{\prime}\left(\eta_{t}\right)=0$, the loss spiral captured by the denominator is switched off.

Likewise,

$$
\sigma_{t}^{q B}=\frac{q_{t}^{\prime}\left(\eta_{t}\right) \eta_{t}}{q_{t}\left(\eta_{t}\right)} \sigma_{t}^{\eta B} \quad \stackrel{(16)}{\Longrightarrow} \quad \sigma_{t}^{\eta B}=-\frac{\frac{\psi_{t}^{B a}+\psi_{t}^{B b}}{1-\eta_{t}}\left(1-\eta_{t}\right)}{1-\left[\psi_{t}^{A a}-\eta\right] \frac{q_{t}^{\prime}\left(\eta_{t}\right)}{q_{t}\left(\eta_{t}\right)}} \sigma^{B},
$$

and the shocks $d Z_{t}^{B}$ are amplified as well.

Shocks affect future flows at least in three ways. First, a drop in net worth $N_{t}$ and $\eta_{t}$ translates automatically into a decline in consumption flow. Agents $A$ save more and try to rebuild their net worth. The terms of trade hedge works through a price effect and a volume effect. After a negative shock, the relative prices $P^{A} / P^{B}$, i.e., the terms of trade, increase. That is, flow profit margins per unit of output increase. However, there is also a volume effect. For higher $P^{A} / P^{B}$ total output volume declines. Total 
revenue for firms in country $A$ increase as long as the price effect dominates the volume effect. Note for the first region $\eta_{t}<\eta^{a}$, the terms of trades $P^{A} / P^{B}=\bar{a} / \underline{a}$ are fixed. That is any further shock is not mitigated by the terms of trade hedge. By symmetry this is also true for the last region with $\eta_{t}>\eta^{b}$.

For the special case of logarithmic utility, we can also explicitly evaluate the drift of $\eta_{t}$. Since the consumption of all agents is proportionate to their net worth, we have

$$
\begin{gathered}
\sigma_{t}^{C^{A} A}=\sigma_{t}^{N A}=\frac{\psi_{t}^{A a}}{\eta_{t}}\left(\sigma^{A}+\sigma_{t}^{q A}\right), \quad \sigma_{t}^{C^{A B}}=\sigma_{t}^{N B}=\frac{\psi_{t}^{A a}}{\eta_{t}} \sigma_{t}^{q B} \\
\sigma_{t}^{C^{B} A}=\sigma_{t}^{N^{B} A}=\frac{1-\psi_{t}^{A a}}{1-\eta_{t}} \sigma_{t}^{q A}, \quad \text { and } \quad \sigma_{t}^{C^{B} B}=\sigma_{t}^{N^{B} B}=\frac{1-\psi_{t}^{A a}}{1-\eta_{t}}\left(\sigma^{B}+\sigma_{t}^{q B}\right) .
\end{gathered}
$$

Then the drift of $\eta_{t}$ divided by $\eta_{t}$ is

$$
\begin{gathered}
\mu_{t}^{\eta}=\left(1-\eta_{t}\right) \frac{\left(\psi_{t}^{A a}\right)^{2}}{\eta_{t}^{2}}\left[\left(\sigma^{A}+\sigma_{t}^{q A}\right)^{2}+\left(\sigma_{t}^{q B}\right)^{2}\right]-\frac{\left(1-\psi_{t}^{A a}\right)^{2}}{1-\eta_{t}}\left[\left(\sigma_{t}^{q A}\right)^{2}+\left(\sigma^{B}+\sigma_{t}^{q B}\right)^{2}\right] \\
\left.-\left[\psi_{t}^{A a} \sigma^{A}+\sigma_{t}^{q A}\right] \sigma_{t}^{\eta A}-\left[\sigma_{t}^{q B}+\left(1-\psi_{t}^{A a}\right) \sigma^{B}\right)\right] \sigma_{t}^{\eta B}
\end{gathered}
$$

We outline the numerical procedure that we employ in Appendix II.

\section{A Special Cases}

Special case of Perfect Substitutes, $s=\infty$. When both output goods are perfect substitutes, then each country produces the good it is better at producing. Country $A$ produces good $a$ and country $B$ good $b$. Also, both goods are sold at the same price of $P^{a}=P^{b}=1 / 2$. The "terms of trade hedge" is switched off altogether. A negative shock is not dampened by an increase in one country's output price. In other words, the market incompleteness has full bite and each country carries the full weight of its risks. In addition, when $\sigma^{A}=\sigma^{B}$ then countries have no need to borrow or lend, and each country functions independently. Risk within each country is perfectly shared and hence country-specific first best solutions can be obtained. A slightly modified version of Proposition 1 holds in this case, but with the variance of shocks twice as large due to the lack of diversification.

Corollary 1 With $s=\infty$, each country fully specializes. The terms of trade hedge is inactive, i.e. $P^{a} / P^{b}=1$. 
In addition, in the symmetric case $\sigma^{A}=\sigma^{B}=\sigma$ there is no international borrowing and lending. Each country $I \in\{A, B\}$ carries its own risk $d Z_{t}^{I}$ and the equilibrium risk-free rate and price of capital are given by

$$
\frac{d r^{F}}{d t}=r+\gamma(\Phi(\iota)-\delta)-\frac{\gamma(\gamma+1) \sigma^{2}}{2} \text { and } q=\frac{\bar{a} / 2-\iota}{d r^{F} / d t+\gamma \sigma^{2}-(\Phi(\iota)-\delta)} .
$$

Proof. This result follows directly from applying first-best analysis to a single country.

The lack of international diversification forces individuals to hold more risk relative to the first-best scenario of Proposition 1. This makes the risk-free asset more attractive, pushing down the equilibrium risk-free rate. This also changes the investment rate $\iota$. Since firms do not borrow or lend, capital shares and wealth shares coincide, i.e. $\psi_{t}^{A a}=\eta_{t}$ and $\psi_{t}^{B b}=1-\eta_{t}$. Essentially in this symmetric case firms are endogenously in autarky. As country $I$ faces shock $d Z_{t}^{I}$, the economy is scaled up or down without affecting prices or the other country. The wealth share of the country increases when it experiences a relatively more favorable shock. In the long-run the system converges to one of the extreme outcomes, where the wealth share is either $\eta=0$ or $\eta=1$. That is, the stationary distribution is degenerate with atoms at the two extreme points. ${ }^{8}$ Interestingly, for the case of log utility the price $q$ and the investment rate $\iota$ coincide with the first best price and investment rate, while the risk-free is lower. ${ }^{9}$

Special case of No Productive Disadvantage, $\underline{a}=\bar{a}$. In this case firms in both countries are equally good at producing both output goods. As a consequence, $P^{a}=P^{b}=1 / 2$ : otherwise firms in both countries would want to shift to produce less of the cheaper good. In this case, the production technology leads to the same outcome as that in the case of perfect substitutability. Like that case, the "terms of trade hedge" is switched off.

\footnotetext{
${ }^{8}$ For the asymmetric case $\sigma^{A}<\sigma^{B}$, absent any lending the risk-free rate would be higher in country $A$. Hence, with open international debt markets, country $A$ would borrow, expand its production capacity, and make in expectation higher profit. In the long-run the wealth share $\eta$ would converge to 1 almost surely.

${ }^{9}$ This can be seen by setting $\gamma=1$ and noting that Equation (24) reduces to $q=\frac{\bar{a} / 2-\imath}{r}$. This equation together with $\Phi^{\prime}(\iota)=1 / q$ jointly determine $q$ and $\iota$. Monotonicity of both equations ensures uniqueness.
} 
Corollary 2 If $\underline{a}=\bar{a}$, the risk-free rate, the price and allocation of capital between countries and the dynamics of wealth shares (but not the allocation of capital to goods a and b) coincide with those in the case of $s=\infty$, as described in Corollary 1.

Viewed differently, Corollary 2 states that it is necessary for the main results of our paper that the two output goods are imperfect substitutes and that the firms in both countries have different expertise.

Corollary 2 also points to an interesting comparative static. As $\underline{a}$ increases towards $\bar{a}$, risk sharing worsens. R\&D spending and product imitations with the aim of improving $\underline{a}$ goes at the expense of the firms in the other country, see, e.g., Samuelson (2004). As firms in both countries engage in such activities, the "terms of trade hedge" worsens, risk sharing becomes limited and welfare reduced. This suggests that policies which increase specialization, by fostering R\&D spending and boosting $\bar{a}$, are much better than "catch-up" policies.

\section{B Numerical Example}

Proposition 2 allows us to characterize the full stochastic equilibrium dynamics of the global economy. For all numerical examples we assume that all agents have logarithmic utility, i.e., $\gamma=1$, and that the investment technology is given by $\Phi(i)=$ $\frac{1}{\kappa}(\sqrt{1+2 \kappa i}-1) .{ }^{10}$ We fix $\sigma^{A}=\sigma^{B}=0.1, \bar{a}=0.14, \underline{a}=0.04, \delta=0.05, \kappa=2, r=0.05$ and consider different elasticities of substitution $s \in\{0.5,1, \infty\}$. Note that due to the symmetry of our setting, it is sufficient to characterize the equilibrium for the wealth shares $\eta \in[0,0.5]$. The equilibrium dynamics are symmetric about $\eta=0.5$.

Panel A of Figure 1 plots the capital shares for the three values of $s$. The solid black line captures the case of $s=1$ (Cobb-Douglas aggregation), the dashed blue line, $s=0.5$, and the dotted magenta line, $s=\infty$. Recall for a reference that the first-best solution of complete markets results in full specialization and with constant capital shares of $\psi^{A a}=0.5$. Under full insurance, the wealth shares also stay constant.

With incomplete markets, as long as $\eta \leq 0.5$ country A still puts all its capital into producing output good $a$. However, as the wealth share $\eta$ declines, so does the capital share $\psi^{A a}$. The capital share declines slower than the wealth share and hence the curve $\psi_{t}^{A a}$ stays (weakly) above the 45 -degree line. This is possible since firms in country $A$ borrow. The level of borrowing depends on the elasticity of substitution

\footnotetext{
${ }^{10}$ The investment technology in this example has quadratic adjustment costs: An investment of $\Phi+\frac{\kappa}{2} \Phi^{2}$ generates new capital at rate $\Phi$.
} 

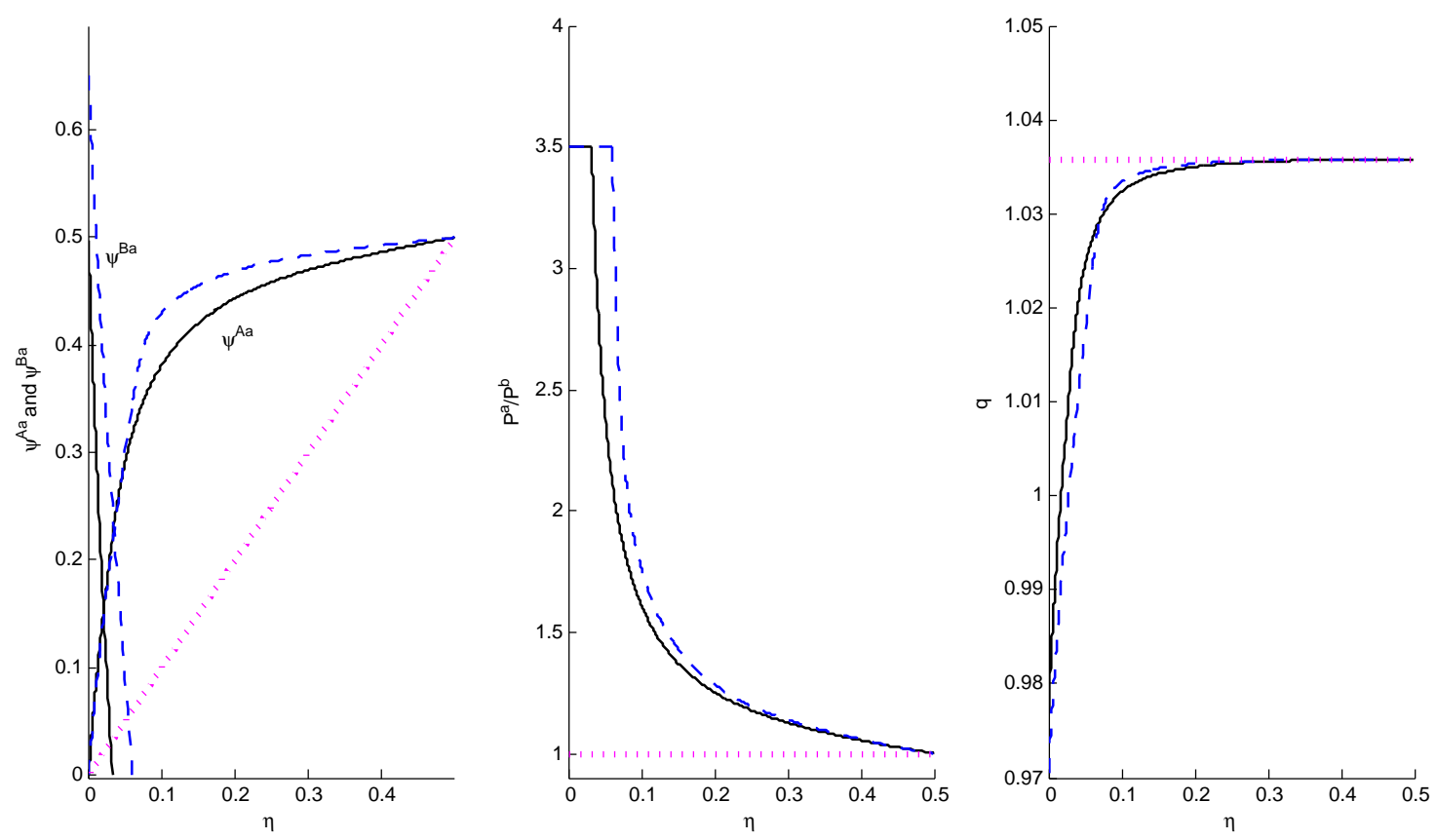

Figure 1: Panel A plots the capital shares $\psi^{A a}$ and $\psi^{B a}$, Panel B plots the terms of trade $P^{a} / P^{b}$ and Panel $C$ plots the price of physical capital $q$, as functions of the wealth share $\eta$, for three different levels of elasticity of substitution: $s=0.5$ in dashed blue, $s=1.01$ (Cobb-Douglas) in solid black, and $s=\infty$ in dotted magenta.

$s$ between both output goods. For the special case with perfect substitutes $s=\infty$ there is no borrowing (Corollary 1 ) and hence the dotted magenta capital share is the 45-degree line. For the cases of $s=.5$ and $s=1$, the difference between $\psi_{t}^{A a}$ and the 45-degree line reflects the fraction of capital that is debt financed. Debt financing reaches its maximum for $\eta$ values around 0.1. A negative shock at that point leads to a sudden and sharp decline in debt financing. Simply the fear of a sudden stop of funding leads firms to cut back their operation. As $\eta$ falls below $\eta^{a}$, firms in country $B$ start producing good $a$ as well, even though they are less productive in doing so. The (decreasing) solid and dashed lines depict $\psi^{B a}$ for $s=1$ and 0.5. For $s=\infty, \psi^{B a}=0$ for any $\eta$.

Panel B of Figure 1 plots the terms of trade, i.e., the price ratio $P^{a} / P^{b}$. The figure shows clearly the "terms of trade hedge." As the wealth share of agents $A$ drops after a negative shock, output good $a$ becomes more scarce. Consequently, the price of good $a$ rises and agents $A$ receive better terms of trade. As soon as the ratio $P^{a} / P^{b}$ rises to $\bar{a} / \underline{a}$, at point $\eta^{a}$, firms in country $B$ start producing good $a$. The terms of trade price ratio $P^{a} / P^{b}$ is then capped at $\bar{a} / \underline{a}$. Notice that the terms of trade improvement after a negative shock is sharper when the goods $a$ and $b$ are worse substitutes. In the limit, as both goods become perfect substitutes, the terms of trade hedge vanishes. 
A remark about empirics is in order: The terms of trade hedge argument suggests a negative association between (relative) GDP growth and the terms of trade. Acemoglu and Ventura (2002) argue that these terms of trade movements introduce de-facto diminishing returns to scale and are the reason for their empirical finding that cross-country world distribution is stable. However, for many commodities this correlation is empirically not strong and can even go in the opposite direction (Backus and Crucini (2000), Berka, Crucini and Wang (2012)). In the end, the sign of the link between output and terms of trade is simply a matter whether supply or demand shocks dominate. In our model, each country's own shock (the shock to its capital stock) is a supply shock, and so naturally produces a negative correlation between the terms of trade and output growth. At the same time, foreign shocks are like a demand shock - a positive shock abroad, say, pushes up demand for domestically produced consumption goods and consequently improves the terms of trade. If shocks have the same volatility and the overall model structure is symmetric, then these countervailing forces work such that the correlation between consumption and the terms of trade in our model ends up being negative (so the terms of trade hedge is operative). ${ }^{11}$ This is consistent with the observation that, as long as a country has the unique expertise in producing a certain good, the link between its output and terms of trade must be negative in the extreme (i.e. as $\eta$ approaches 0 or 1 ). This, however, does not preclude the possibility that output and terms of trade move together locally. Panel B shows that, in our model, the link between output and terms of trade is monotonic in $\eta$, but in more general settings this need not be so. For example, Pavlova and Rigobon (2007) develop a framework in which demand shocks lead to a locally positive association between domestic consumption and terms of trade. They achieve this by scaling country-level utility functions via arbitrary stochastic processes (interpreted as demand shocks), and by assuming cross-country heterogeneities in preferences (home-good bias). Domestic demand shocks thus disproportionately increase demand for domestic goods, and so terms of trade and consumption go hand in hand.

Panel $\mathrm{C}$ of Figure 1 shows the price of physical capital $q$ for the three different values of $s$. Recall that the reinvestment rate per unit of capital $\iota$ is directly related to the price of capital $q$ through the first order condition $\Phi^{\prime}(\iota)=1 / q_{t}$. A higher capital price $q$ translates to a higher investment rate.

Figure 2 characterizes the stochastic dynamics of the state variable: country $A^{\prime}$ s wealth share $\eta$. This differs from how macroeconomists typically represent the stochas-

\footnotetext{
${ }^{11}$ With incomplete markets, domestic wealth and so consumption are more sensitive to domestic supply shocks than to foreign shocks. Complete markets, in contrast, involve perfect risk-sharing.
} 

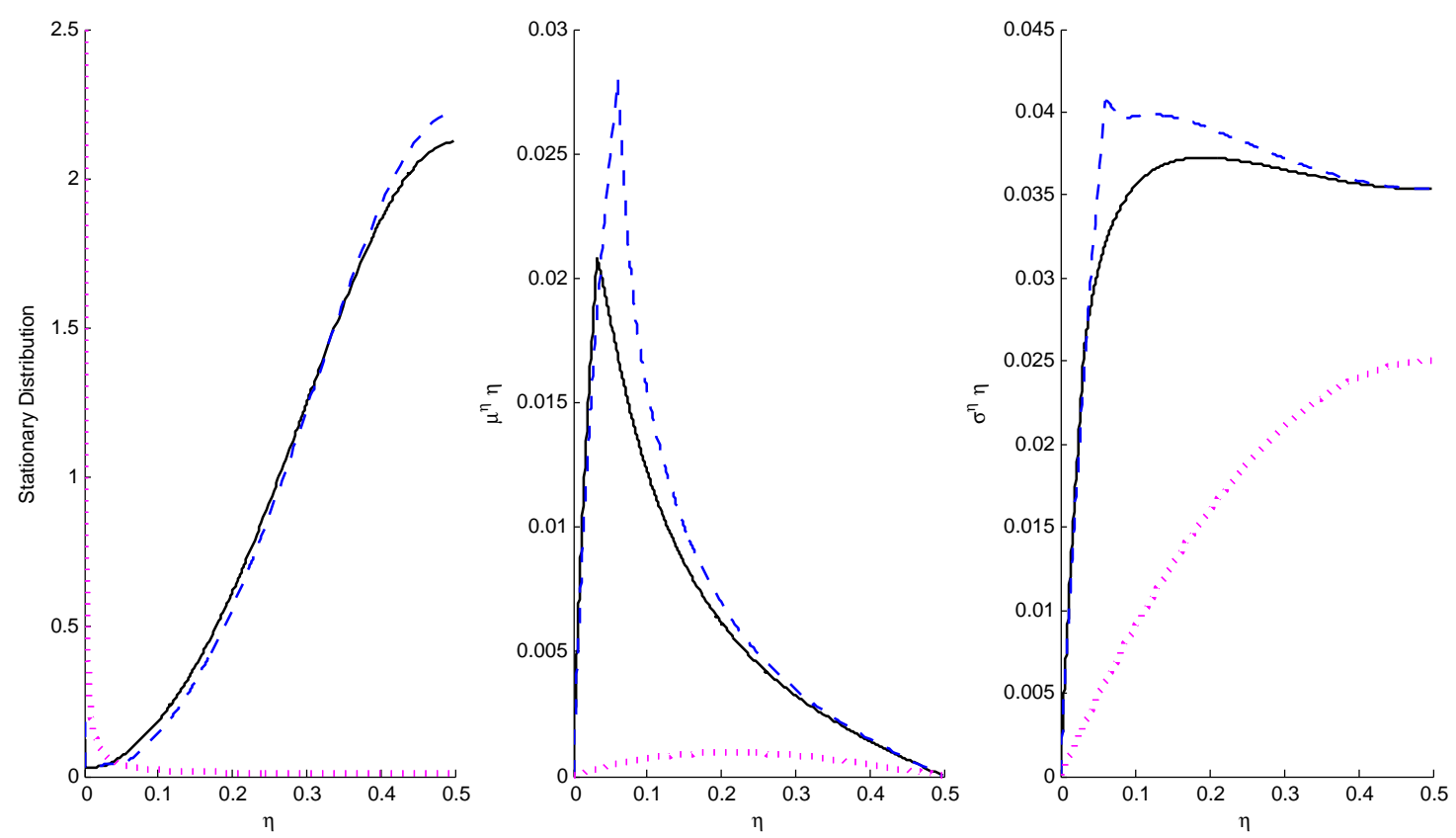

Figure 2: Panel A plots the stationary distribution, Panel B the drift and Panel C the volatility of wealth shares $\eta$ for three different levels of elasticity of substitution: $s=0.5$ in dashed blue, $s=1.01$ (Cobb-Douglas) in solid black, and $s=\infty$ in dotted magenta.

tic dynamics of an economy. It is standard to plot impulse response functions. However, impulse response functions only plot the expected response of a variable near a specific reference point (e.g. the steady state). The drift and volatility of the state variable, depicted in Panels B and C of Figure 2, provide a full characterization of the dynamical system for any starting point, including the volatility dynamics. The drift of $\eta$ (Panel B) reveals that the system has a basin of attraction at $\eta=0.5$. Whenever the system falls below $\eta=0.5$, the positive drift pushes it back towards $\eta=0.5$. Similarly, for $\eta>0.5$, the system drifts back to $\eta=0.5$ as the drift is negative in the range $\eta \in(0.5,1)$. Panel $C$ depicts the volatility of $\eta$.

Panel A plots the stationary distribution for $\eta \in[0,0.5]$. Two features stand out. First, lower output good substitutability leads to a tighter distribution of wealth shares. For smaller $s$ the "terms of trade hedge" ensures that countries are better insured against redistributive shocks despite the fact that no risky claims can be traded in international markets. In the limit as $s$ goes to infinity and both output goods become perfect substitutes, the stationary distribution becomes degenerate with atoms only at $\eta=0$ and $\eta=1$. Recall that the first-best complete-market solution implies a degenerate stationary distribution that is concentrated at the initial $\eta$. Second, unlike in Cole and Obstfeld (1991) the Cobb-Douglas case does not lead to full insurance nor 
to the first best outcome in our setting. The stationary distribution does not degenerate to an atom. What explains this difference? In Cole and Obstfeld (1991) a positive productivity shock for country $A$ is like a positive endowment shock of good $a$. Supplying more $a$ goods worsens country As terms of trade. In our setting the terms of trade hedge is less pronounced, since the shock is in terms of the capital good $K$. After a positive shock, agents in country $A$ sell off some of the (composite) capital goods instead of only selling off output good a. In addition, in our economy capital is persistent and hence a productivity shock has long-lasting implications, while in Cole and Obstfeld (1991) capital is short-lived, it depreciates fully in each period. Our results also show that their resolution of the international diversification puzzle in the case of Cobb-Douglas preferences is particular to their setting.

Even though the terms of trade hedge is not perfect in our setting, and consequently the wealth share $\eta$ is not constant, a distressed economy typically grows relatively fast out of its malaise. Panel B of Figure 2 reveals that the drift of $\eta$ is high for low, but not extremely low, $\eta$ values. Competition is depressed and profits (corrected for legacy losses) are high. Calvo (1998) coined this empirical phenomenon as "Phoenix miracle". Importantly, the Phoenix miracle vanishes for very extreme $\eta$ values, when the poor economy is extremely impaired.

\section{Sudden Stops and Runs}

Sudden stops refer to a sharp decline in credit flows. The total amount of country $A$ debt in our model is given by $\left(\psi_{t}^{A a}-\eta_{t}\right) q_{t} K_{t}$, i.e., total assets minus net worth. Figure 3 depicts the total debt level for country $A$ for $\eta \in[0,0.5]$, normalizing $K_{t}$ to one. In our model sudden stops occur naturally on the equilibrium path due to the amplification of exogenous shocks and corresponding decline of wealth in an individual country. In addition, there is a possibility of sunspots triggering a sudden decline in capital price and outstanding debt of one of the countries.

Definition 1 A sudden stop occurs when either:

(i) an adverse fundamental shock triggers a percentage decline in outstanding debt that exceeds the percentage decline in net worth, i.e. the leverage ratio falls. For country A this occurs when the elasticity $\frac{\partial\left(\psi^{A a}-\eta\right)}{\partial \eta} \frac{\eta}{\psi^{A a}-\eta}>1$, or equivalently, $\frac{\partial \psi^{A a}}{\partial \eta}>\frac{\psi^{A a}}{\eta}$.

(ii) a sunspot triggers a sudden capital price drop from $q$ to $\hat{q}$, accompanied by a drop in $\eta$ to $\tilde{\eta}$ and a decline in debt. In this event, the wealth of country A (per unit of capital) jumps to $\tilde{q} \tilde{\eta}=\max \left(\eta q+\psi^{A a}(\tilde{q}-q), 0\right)$. The drop in capital is a self-fulfilling if $\tilde{q}=q(\tilde{\eta})$, i.e. the 
new capital price level is sustainable in equilibrium.

Sudden Stops within Baseline Equilibrium. Formally, the total debt amplification effect is captured by

$$
\sigma_{t}^{\text {Debt }}{ }^{A}=\left\{1+[\frac{q_{t}^{\prime}\left(\eta_{t}\right) \eta_{t}}{q_{t}}+\underbrace{\frac{\left[\left(\psi_{t}^{A a}\right)^{\prime}\left(\eta_{t}\right)-1\right] \eta_{t}}{\psi_{t}^{A a}-\eta_{t}}}_{\text {leverage ratio sensitivity }} \underbrace{\frac{\psi_{t}^{A a}}{\eta_{t}}\left(1-\eta_{t}\right)}_{\eta \text {-amplification }} \frac{\left.\psi_{t}^{A a}-\eta_{t}\right] \frac{q_{t}^{\prime}\left(\eta_{t}\right)}{q_{t}}}{-\frac{\psi_{t}^{A}}{A}}\} \sigma^{A},\right.
$$

where the " $\eta$-amplification factor" is directly taken from Equation (20). If the leverage ratio declines as $\eta$ declines, the "leverage ratio sensitivity" factor is larger than 1. Likewise for $d Z^{B}$-shocks, one can derive an analogous amplification factor using Equation (21). Recall that $q^{\prime}(\eta)$ in the denominator reflects the amplification due to the loss spiral.

Whether and to what extent sudden stops can occur within the baseline equilibrium - that is, the leverage ratio, $\frac{\psi^{A a}}{\eta}$, falls as $\eta$ declines - depends on the market illiquidity of capital, $q^{\prime}(\eta)$. Market illiquidity, in turn, is driven by technological illiquidity, captured by the adjustment cost parameter $\kappa$. With $\kappa=0$, both technological and market liquidity of capital are perfect as the price is always $q=1$, as shown by the dashed blue line in the right panel of Figure 3.

The case with adjustment costs of $\kappa=2$ is depicted by the black curve in the right panel of Figure 3. As long as output goods are not perfect substitutes, i.e. $s<\infty$ and $\underline{a}<a$, the price of capital $q(\eta)$ declines as $\eta$ drops. There is aggregate price impact and hence market liquidity is not perfect. In this case, debt declines sooner, at higher level of $\eta$. However, in our example a sudden stop defined by $\frac{\partial \psi^{A a}}{\partial \eta}>\frac{\psi^{A a}}{\eta}$ does not occur. Graphically on the left panel, there are no $\eta$-values for which the slope of the tangent $\frac{\partial \psi^{A a}}{\partial \eta}$ of the (normalized) debt level is higher than the slope $\frac{\psi^{A a}}{\eta}$ of the secant, the line that goes through $(0,0)$ and $\left(\eta, \psi^{A a}(\eta)\right)$.

Irreversibility of investments is an extreme form of technological illiquidity, which assumes infinite adjustment costs for disinvestment $\iota<0$. The green dashed-dotted curves in Figure 3 depict the case in which disinvestment adjustment costs are $\kappa_{l<0}=$ 100 , while investment adjustment costs stay at $\kappa_{l}>0=2$. The right panel shows clearly that now the price drop for low $\eta$ values is much more pronounced. More importantly, 

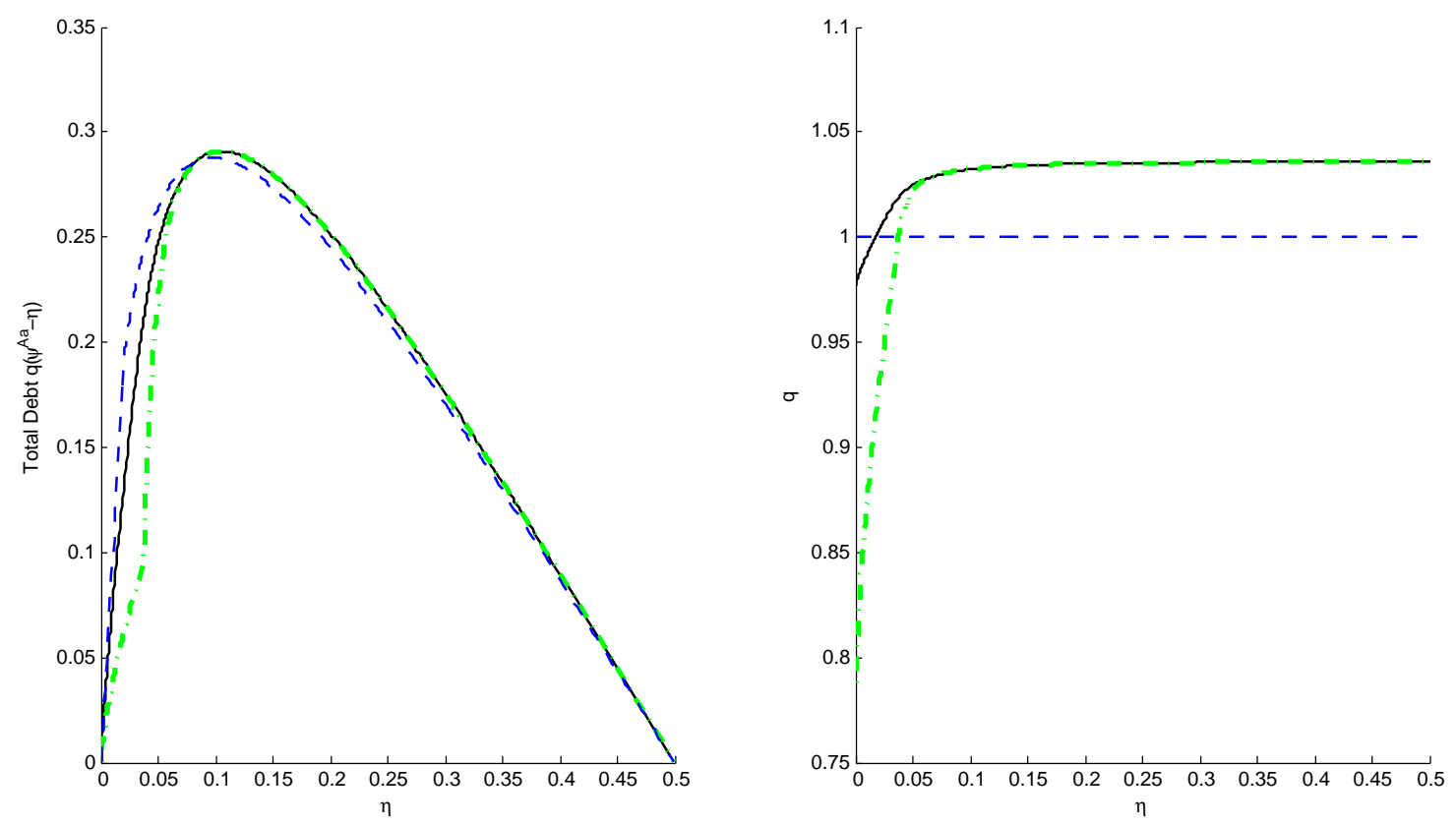

Figure 3: Panel A depicts Country $A^{\prime}$ s (normalized) debt level $q(\eta)\left[\psi^{A a}-\eta\right]$ as a function of its wealth share $\eta$, for three different levels of adjustment costs functions: $\kappa_{l<0}=\kappa_{l>0}=0$ in dashed blue, $\kappa_{l<0}=\kappa_{\iota>0}=2$ in solid black, $\kappa_{l<0}=100$ and $\kappa_{\iota>0}=2$ in dashed-dotted green. Panel B depicts the corresponding price functions for $q(\eta)$. As in our benchmark case we set $s=1.01$.

the price $q(\eta)$ is not always concave due to the kink. Hence for a whole range $\eta$-values $\frac{\partial \psi^{A a}}{\partial \eta}>\frac{\psi^{A a}}{\eta}$ and therefore sudden stops can occur.

Sudden stops in Sunspot Equilibria. With sufficiently low market liquidity, i.e., sufficiently high $q^{\prime}(\eta)$, a non-fundamental sunspot can trigger the second form of a sudden stop - a jump in price of capital and wealth share. Such a jump occurs even absent an adverse fundamental shock. That is, the contraction can be entirely self-fulfilling.

Intuitively, as each agent $A$ shrinks his balance sheet by fire-selling assets and repaying his debt, the price of capital $q$ drops and erodes all agents $A^{\prime}$ s net worth. Competing agents from the same country, who have no contractual arrangement with each other, erode the price of the joint capital good and thereby impose negative spillover effects on another. The externality works through the price $q_{t}$, which each agent $A$ takes as given. Note the difference from a classic bank run in which lenders withdraw funding and cause a crunch in credit supply. Here the decline in total credit is a credit demand effect. Borrowers cut back since they are worried about downside risks and about hitting the insolvency boundary condition where net worth is zero.

More formally, consider a price drop from current point $q(\eta)$ to say $\tilde{q}$. This price 
drop leads to a new net worth $N+(\tilde{q}-q) \psi^{A a} K$, which translates to a new wealth share of 12

$$
\frac{N+(\tilde{q}-q) \psi^{A a} K}{\tilde{q} K}=\frac{\eta q+(\tilde{q}-q) \psi^{A a}}{\tilde{q}} .
$$

The economy is only vulnerable to sudden stops due to sunspots if $q(\eta)$ is sufficiently steep in $\eta$ and the initial debt level $q(\eta)\left[\psi^{A a}-\eta\right]$ is sufficiently large. For large enough starting points $\eta, q^{\prime}(\eta)$ is too small. At the other extreme, for small enough $\eta$ the debt level is not high enough to generate a second equilibrium. In short, the economy is only vulnerable to sudden stop runs only for a range of $\eta \in[\underline{\eta}, \bar{\eta}]$. Within that range there exist exactly two sun-spot equilibria, as long as $q(\eta)$ is concave and $\tilde{\eta}(\tilde{q})$ convex. Note that we considered only unanticipated self-fulfilling run equilibria where the arrival rate of the sunspots is zero. The economy is most vulnerable to unanticipated sunspots since agents do not prepare for these. Proposition 3 formalizes this result.

Proposition 3 For sufficiently low market liquidity, such that $q(\eta)$ is sufficiently (concavely) increasing in $\eta$, there exists a vulnerability region $[\eta, \bar{\eta}]$ in which country $A$ is vulnerable to unanticipated self-fulfilling jumps in $q$ triggered by a sunspot absent a fundamental shock. Jumps are discontinuous in price and wealth share. Within the vulnerability region there are two sunspot equilibria of which one results in the absorbing disaster state $\eta=0$. The outcome is analogous for country $B$.

The proof of the proposition follows directly by construction and continuity around the region. The concavity of $q(\eta)$ and strict convexity of the hyperbola $\tilde{\eta}(\tilde{q})$ implies that there are at most two sunspot equilibria and that there are no small jump equilibria. The finding that small jumps are not self-sustaining can be seen as a robustness property of the baseline equilibrium.

One might suspect that when agents of the poorer country sell off their physical capital at fire sale prices foreigners benefit at their expense. Indeed the foreigners' wealth shares rise, but surprisingly they are ultimately also worse off. In short, sudden stops are not only associated with large wealth redistributions, but even more importantly with wealth destruction in both countries. Section IV's welfare analysis shows sudden stops lead to Pareto inferior outcomes independent of whether they are associated with multiple equilibria or amplification effects.

\footnotetext{
${ }^{12}$ If we were to plot this equation in right panel of Figure 3 it would be an upward sloping convex hyperbola that goes through the initial starting point $q(\eta)$. The hyperbola potentially crosses $q(\eta)$ at the initial starting point and possibly in addition at a lower price level $q(\tilde{\eta})$. If so, then a jump to absorbing sate $\eta=0$ is also possible.
} 
From a policy perspective, ex-post crisis management should avoid wealth destructive sudden stops and ex-ante credit flow management should reduce excessive build-up of liquidity mismatch due to short-term debt financed projects with low technological liquidity. Macroprudential policies instruments that limit leverage and liquidity mismatch might be the appropriate policy tools.

\section{Closed Capital Account: Capital Controls}

Let us now consider the case in which the capital account is closed or macroprudential regulation prevents borrowing. Agents in the economy cannot tap in to the international debt market but can still trade goods $a$ and $b$ as well as physical capital. Then asset-pricing conditions (12) and (13) still hold. Each country has its own risk-free rate characterized by Equation (11) for country $A$ and an analogous equation for country $B$ based on the consumption process in country $B$.

The following proposition characterizes a procedure to compute the equilibrium under the assumption of logarithmic utility.

Proposition 4 Suppose that all agents have logarithmic utility $(\gamma=1)$. Then the state space is divided into three regions. In the middle region, $\eta \in\left[\eta^{a}, \eta^{b}\right]$, all agents engage only in their most productive technology (full specialization), i.e. $\psi_{t}^{A a}=\eta_{t}, \psi_{t}^{B b}=1-\eta_{t}$ and $\psi_{t}^{B a}=\psi_{t}^{A b}=0$, and the price of capital $q_{t}$ satisfies

$$
\left[\frac{1}{2}(\bar{a} \eta)^{\frac{s-1}{s}}+\frac{1}{2}(\bar{a}(1-\eta))^{\frac{s-1}{s}}\right]^{\frac{s}{s-1}}-\iota(q(\eta))=r q(\eta) .
$$

In the region $\left[0, \eta^{a}\right)$, in which agents of country B use capital to produce good a, the price of capital and the production of agents $B$ are determined jointly by the equations

$$
\begin{gathered}
\bar{a} P^{b}=\underline{a} P^{a}, \\
{\left[\frac{1}{2}\left(\bar{a} \eta+\underline{a}\left(1-\eta-\psi^{B b}\right)\right)^{\frac{s-1}{s}}+\frac{1}{2}\left(\bar{a} \psi^{B b}\right)^{\frac{s-1}{s}}\right]^{\frac{s}{s-1}}-\iota(q(\eta))=r q(\eta) .}
\end{gathered}
$$

At point $\eta^{a}, \psi^{B b}$ reaches $1-\eta_{t}$ and $q(\eta)$ reaches the level defined by (26). The law of motion 
of $\eta_{t}$ over the entire range $\left[0, \eta^{b}\right)$ is given by

$\frac{d \eta_{t}}{\eta_{t}}=\left(\frac{\bar{a} P_{t}^{a}-\iota_{t}}{q_{t}}-r-\left(1-\eta_{t}\right)\left[\eta_{t}\left(\sigma^{A}\right)^{2}-\left(1-\eta_{t}\right)\left(\sigma^{B}\right)^{2}\right]\right) d t+\left(1-\eta_{t}\right)\left[\sigma^{A} d Z_{t}^{A}-\sigma^{B} d Z_{t}^{B}\right]$.

The region $\left(\eta^{b}, 1\right]$, where agents $A$ produce good $b$, is determined symmetrically to the region $\left[0, \eta^{a}\right)$.

Proof. See Appendix C.

As before we illustrate our findings within specific numerical examples. To ease the comparison with the previous section we apply the same parameter values. Instead of focusing on different levels of substitutions, in this section we stress the difference between outcomes under open and closed capital accounts.

Panel A of Figure 4 shows the difference between a global economy with and without capital controls. For equal wealth shares, i.e., for $\eta=0.5$, agents are fully specialized in both cases. However, as $\eta$ declines, production in country $A$ falls faster under closed capital account than it does under the open capital account. The reason is that firms in country $A$ can issue short-term debt to agents in country $B$. Panel A reveals that $\psi^{A a}$ is significantly higher in the case without capital controls (increasing black solid curve) than in the case with capital controls (red dashed increasing 45degree line). With capital controls agents in country $B$ start producing the output good $a$ much sooner at higher $\eta$ values. As a result, the economy with open capital accounts exhibits a higher degree of specialization than the economy with closed capital accounts.

Panel $\mathrm{B}$ shows the difference in the terms of trade, the relative price ratio $P^{a} / P^{b}$. Without capital controls each agent in country $A$ borrows in order to hold a larger fraction of the global physical capital stock, resulting in greater output of good $a$. This undermines the terms of trade improvement that occurs under strict capital controls. With capital controls the terms of trade improvement is sharper. In addition, an open capital account is subject to a pecuniary externality. Each individual agent ignores the effect of his production on his fellow countrymen; by borrowing and operating on a larger scale, he raises output and depresses the price for others.

Cutting down on debt financing also pushes down the price of physical capital $q$ as shown in Panel C of Figure 4. This lowers the net worth. In terms of wealth shares, it hits the country which is levered further. As pointed out above the loss liquidity spiral amplifies the initial shock even further. 

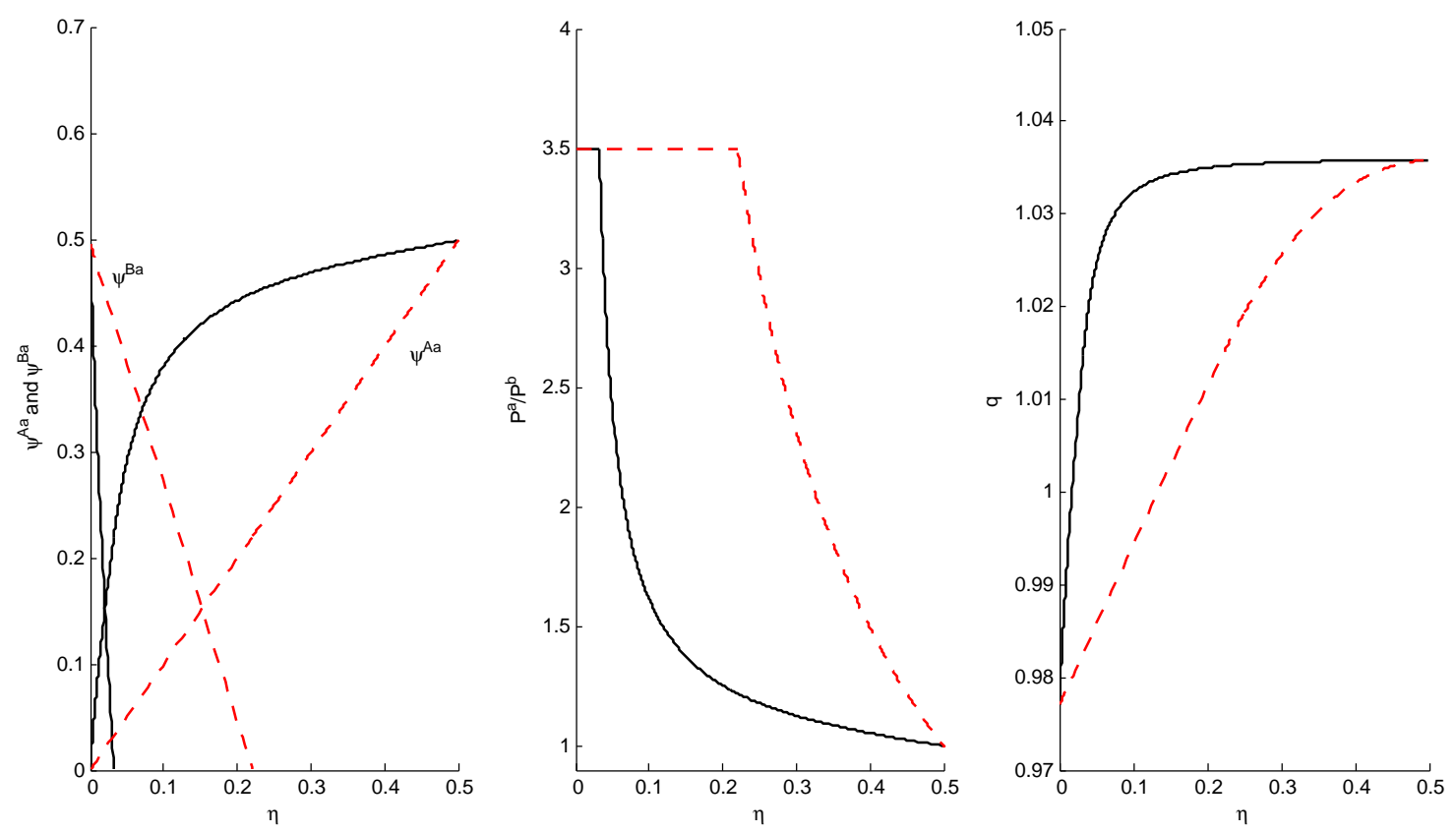

Figure 4: Panel A, B and C contrast the capital shares $\psi^{A a}$ and $\psi^{B a}$, the terms of trade $P^{a} / P^{b}$ and the price of physical capital $q$ of an economy without and with capital controls (black solid versus red dashed curves) assuming an elasticity of substitution of $s=1.01$ (close to Cobb-Douglas).
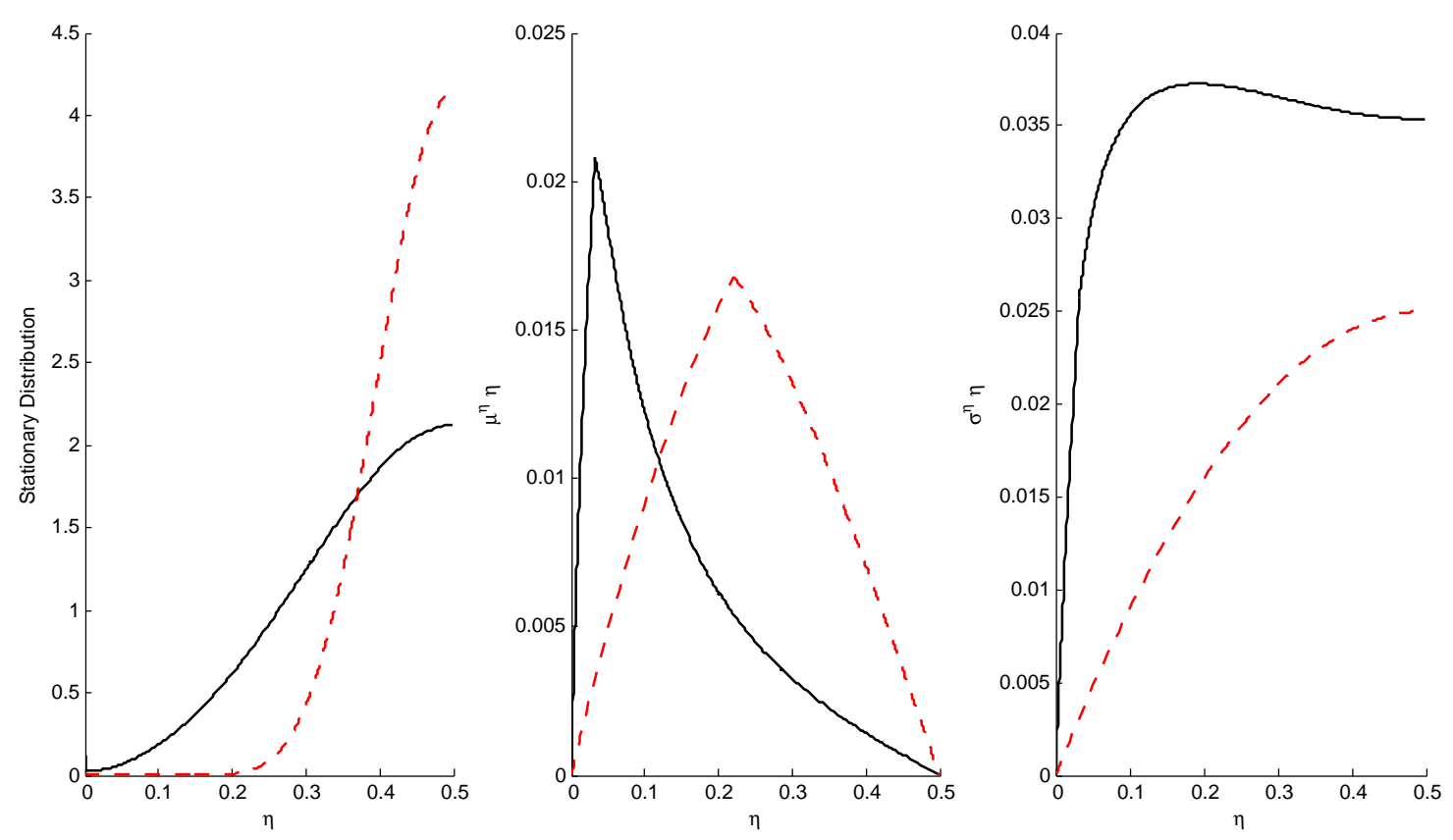

Figure 5: Panel A plots the stationary distribution, Panel B the drift and Panel $C$ the volatility of wealth shares $\eta$ for the global economy without capital controls (black solid curves) and with capital controls (red dashed curves) for an elasticity of substitution coefficient of $s=1.01$. 
Figure 5 shows the stability profile of an economy without and with capital control. Overall, debt financing increases specialization, it leads to better allocation of resources and boosts economic growth in normal times. However, it comes at the price of reduced economic stability. Panel A of Figure 5 shows this: the stationary distribution of the wealth share has more mass at the extremes in a global economy without capital controls. Panel $\mathrm{C}$ shows that the volatility of $\eta$ is much higher with an open capital account.

\section{Welfare Analysis}

While short-term debt restrictions, like capital controls, can improve risk sharing through the terms-of-trade hedges, they can also lower average economic growth. In our incomplete-market setting, capital controls interact with many pecuniary externalities. To answer whether capital controls are desirable, it is important to conduct a formal welfare analysis.

Pecuniary Externalities. In complete markets, negative pecuniary externalities on competitors balance out against positive externalities on consumers, leading to a Pareto efficient outcome. In an incomplete-market setting, such as ours, pecuniary externalities can lead to inefficiencies, see Geanakoplos and Polemarchakis (1986). For example, when agents who maximize individual utility affect prices as a group, they affect the amount risk sharing in the economy, which is limited by market incompleteness. While $\eta$, which characterizes the wealth distribution, remains constant in a complete-market setting, in our setting price changes shift the wealth distribution. Firms in one country affect prices in two ways. First, when overcapitalized, they decide at what point to start competing with the firms in the other country. Second, when undercapitalized, they set their scale of production choosing the amount of international borrowing. While each individual firm's decisions are too small to affect prices, as a group they do.

When a firm decides to start producing the good for which it has less expertise, it takes output prices as given. Each firm in a country ignores that they as a group cap the other country's output price. This ruins the terms of trade hedge for the firms in the other county as soon as the ratio $P^{a} / P^{b}$ reaches $\bar{a} / \underline{a}$ or $\underline{a} / \bar{a}$. Capital controls have no impact on this pecuniary externality. ${ }^{13}$

\footnotetext{
${ }^{13}$ If one were to endogenize $\underline{a}$, even further inefficiency would arise whose cause is not a pecuniary
} 
The second pecuniary externality stems from firms' borrowing decisions to scale up their operation. This decision affects mainly competing firms in the home country. As each domestic firm borrows after an adverse shock to keep production high, the firms as a whole limit the price increases of their output. Each firm does not internalize that its borrowing undermines the terms of trade hedge. On the other hand, if borrowing is limited, competition is reduced and profit margins rise. This can lead to higher profits and help firms recapitalize themselves more quickly through higher retained earnings. Of course, the dose of the borrowing limits has to be right; limits that are too draconian are counterproductive. This is the case if higher profit margins do not offset the losses from the decreased volume, as it is the case when foreign firms enter to compete with the domestic firms. ${ }^{14}$

Pecuniary externalities also work through the price of capital $q$. When firms decide how much short-term debt to issue in order to acquire physical capital from abroad, they do not internalize that effect of their leverage on the sensitivity of the price $q$ to shocks. As all firms in a country increase their leverage ratio, the price of capital $q$ is subject to a much sharper drop.

While in this paper we simply ask whether the crude policy of closing the international capital flow can increase welfare, better outcomes can be attained with more general policies. International lending does not have to be shut down fully, and capital flows across borders can be regulated with taxes that directly target the size of the pecuniary externalities.

Pecuniary externalities and market incompleteness are the reasons for the constrainedinefficient equilibrium outcome. Optimization by the social planner would account for the effects price changes, and, in our case, the terms of trade hedges. That is, even though the planner may have no more freedom and face the same incomplete-market frictions as the agents, he can achieve higher welfare.

Welfare Calculations. Pecuniary externalities help us to identify the source of constrained inefficiency of the market outcome. However, to figure out the extent of the inefficiency and the welfare impact of various policy measures we have to conduct an explicit welfare analysis. Policy measures that reduce uncertainty can be welfare enhancing even when they result in a slightly lower growth rate. Hence, we calculate

externality. Each country as a whole has an incentive to promote measures that increase its $\underline{a}$. This improves the country's terms of trade at the expense of the other country, see Samuelson (2004). As both countries engage in such activities they undermine each others' terms of trade hedges.

${ }^{14}$ That is, capital controls can improve risk sharing from terms-of-trade hedges only when specialized domestic firms do not have viable foreign competitors. 
the value functions reflecting the discounted future expected utility stream for both types of agents.

In this section we focus on a setting with logarithmic utility, i.e. $\gamma=1$. In this case value functions take the simple form

$$
V\left(n_{t}, \eta_{t}\right)=\frac{\log n_{t}}{r}+h\left(\eta_{t}\right)
$$

To understand this form of value functions, note that if we change the net worth of an agent by a factor of $\alpha$, the agent's optimal consumption also changes by a factor of $\alpha .{ }^{15}$ Since $\log \left(\alpha c_{t}\right)=\log (\alpha)+\log \left(c_{t}\right)$, the agent's utility increases by $\log (\alpha) / r$. This is reflected in the form (30). The wealth-independent term $h\left(\eta_{t}\right)$ depends on the agent's investment opportunities, summarized by the state variable $\eta_{t}$. The first term is increasing in agent A's own wealth, while the $h\left(\eta_{t}\right)$-term tends to be decreasing in $\eta_{t}$, the wealth share of other agents in the same country. As $\eta_{t}$ declines competing firms in the same country decrease their output, the output price rises and with it expected profits. The exact form of $h(\eta)$ depends on the market frictions.

For country $A$ the value function can be decomposed into

$V\left(N_{t}, \eta_{t}\right)=\frac{\log N_{t}}{r}+h\left(\eta_{t}\right)=\frac{\log \left(\eta_{t} K_{t} q_{t}\right)}{r}+h\left(\eta_{t}\right)=\frac{\log \eta_{t}}{r}+\frac{\log K_{t}}{r}+\underbrace{\frac{\log q\left(\eta_{t}\right)}{r}+h\left(\eta_{t}\right)}_{H\left(\eta_{t}\right)}$.

For clarity, we normalize the initial size of the economy to $K_{0}=1$. Hence, the second term drops out. Let us combine the third and fourth terms to $H(\eta)=$ $\log (q(\eta)) / r+h(\eta)$. Proposition 5 shows that, after manipulating the HJB equation, $H(\eta)$ has to solve a second order ordinary differential equation.

Proposition 5 In the competitive equilibrium, $H(\eta)=\log (q(\eta)) / r+h(\eta)$ satisfies the following second order differential equation:

$$
\begin{gathered}
r H(\eta)=\log (r q(\eta))+\frac{\mu_{t}^{\eta}}{r}-\frac{\left(\sigma_{t}^{\eta A}\right)^{2}+\left(\sigma_{t}^{\eta B}\right)^{2}}{2 r}+\frac{\Phi(\iota)-\delta}{r} \\
-\frac{\left(\psi^{A a}+\psi^{A b}\right)^{2}\left(\sigma^{A}\right)^{2}+\left(\psi^{B a}+\psi^{B b}\right)^{2}\left(\sigma^{B}\right)^{2}}{2 r}+\mu_{t}^{\eta} \eta H^{\prime}(\eta)+\frac{\left(\sigma_{t}^{\eta A}\right)^{2}+\left(\sigma_{t}^{\eta B}\right)^{2}}{2} \eta^{2} H^{\prime \prime}(\eta) .
\end{gathered}
$$

For agents $B$ an analogous $O D E$ applies, and their value function is given by $V^{B}\left(N_{t}^{B}, \eta_{t}\right)=$ $\log \left(N_{t}^{B}\right) / r+H\left(1-\eta_{t}\right)$ in the symmetric case $\sigma^{A}=\sigma^{B}=\sigma$.

\footnotetext{
${ }^{15}$ In fact, this is true for any CRRA utility.
} 


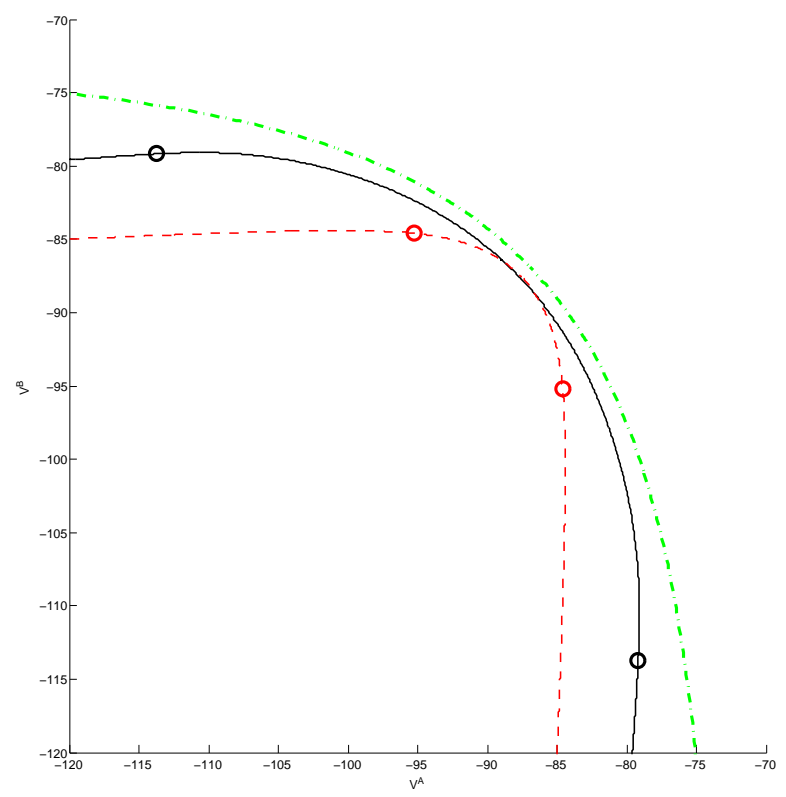

Figure 6: Welfare frontier for agents in country A (x-axis) and agents in country B (y-axis). The first-best solution is depicted by the outer dashed-dotted green frontier. The market equilibrium frontier without capital controls is given by the black frontier, while the frontier under strict capital controls is depicted by the red dashed curve. The circles on the frontiers mark the switching points, $\eta^{a}, \eta^{b}$, when full specialization starts or ends.

Proof. See Appendix D.

The exact form of $H(\eta)$ depends on the market frictions and whether capital controls are imposed or not. Once we have solved the ODE for $H(\eta)$ for both types of agents, we find out the welfare of agents $A$ and $B$ for any current wealth share $\eta$. As one varies $\eta$ one walks along the frontier. Any $\eta$ corresponds to the point $\left(V^{A}(\eta), V^{B}(\eta)\right)=(\log (\eta) / r+H(\eta), \log (1-\eta) / r+H(1-\eta))$ on the frontier.

Figure 6 plots the frontier of value functions for agents in country $A$ on the x-axis and for agents in country $B$ on the y-axis. The outer frontier, given by the green dashed-dotted curve, depicts the first best outcomes that arise as equilibrium outcomes under complete markets. The values themselves turn out to be negative, which is not surprising given that the value function is of the log form, like the utility function. The circles on the various frontiers indicate the points $\eta^{a}$ and $\eta^{b}$. In the middle region $\eta \in\left[\eta^{a}, \eta^{b}\right]$ firms exclusively produce output goods they are good producing at. In a world with capital controls the middle region seems smaller. This does however not automatically imply that the economy spends less time in this region, since in that case the stationary distribution is more concentrated around $\eta=.5$

The first best frontier is the Pareto frontier, and so it is strictly decreasing. As one moves along the frontier, the value of agents $A$ increases only when the value of 
agents $B$ declines. The first best solution is particularly simple as in this case $H(\eta)$ is constant. Note that in the case of log utility the Pareto weight $\lambda$ that the planner assigns to agents $A$ coincides with agent $A$ 's consumption share and wealth share $\eta{ }^{16}$ For the first best solution, the ODE in Proposition 5 reduces to

$r H(\eta)-\log (q(\eta))=\log (r)+\frac{\left(\sigma^{N A}\right)^{2}+\left(\sigma^{N B}\right)^{2}}{2 r}+\frac{1}{r}\left[\frac{\bar{a} P^{a}-\iota}{q}+\Phi(\iota)-\delta-\sigma^{A} \sigma^{N A}-r\right]$,

where $\sigma^{N A}=\sigma^{A} / 2$ and $\sigma^{N B}=\sigma^{B} / 2$ and $q$ is given in Proposition 1.

Returning to Figure 6, the incomplete markets outcome with an international debt market is given by the solid black curve. Notice that the black frontier is inward bending for very skewed wealth distributions, i.e. for $\eta$ sufficiently close to 0 or $1 .^{17}$ In other words, the frontier is not necessarily a Pareto frontier. For low enough values of $\eta$ an unanticipated wealth transfer from agents in country $B$ to agents in country $A$, e.g. in form of a bailout or debt relief program, can make both types of agents better off. (By symmetry, for high enough $\eta$, the reverse transfer can lead to Pareto improvement.) The intuition for this feature is that with extreme wealth inequality it would be better to distribute wealth to the poor country. Firms in the poor country increase their output which lowers their output price. ${ }^{18}$ Agents from the richer country benefit from the lower output price, justifying the initial wealth transfer. Since each individual rich agent takes prices as given he would be unwilling to do such a transfer. Only a government can coordinate such a transfer that internalizes the pecuniary externalities.

Looking at Figure 6 one might get the impression that transfers should occasionally occur and capital controls are primarily welfare destroying except for some values of $\eta$ close to $1 / 2$. The conclusion one could draw is misleading for two reasons. First, assuming that $\eta$ is drawn from the stationary distribution, values of $\eta$ for which a transfer from the rich to the poor country is Pareto improving are rare. Most of the time the economy stays close to $1 / 2$. Second, capital controls are actually mostly welfare improving since the system is rarely outside the region where the dashed red capital control frontier is inside the solid black welfare frontier.

It is therefore wise to look at welfare for each type of agent from a different angle,

\footnotetext{
${ }^{16}$ Recall from Equation (14) for general risk aversion coefficient $\gamma$ the consumption share under first best is $(\lambda)^{\frac{1}{\gamma}} /\left[(\lambda)^{\frac{1}{\gamma}}+(1-\lambda)^{\frac{1}{\gamma}}\right]$ (see Appendix A)

${ }^{17}$ As one increases the adjustment costs for disinvestment the frontier becomes more inward bending.

${ }^{18}$ Note even though for $\eta<\eta^{a}\left(\eta>\eta^{b}\right)$ the immediate terms of trade are temporarily fixed at either $\bar{a} / \underline{a}(\underline{a} / \bar{a})$, a price in the (near) future becomes more likely.
} 

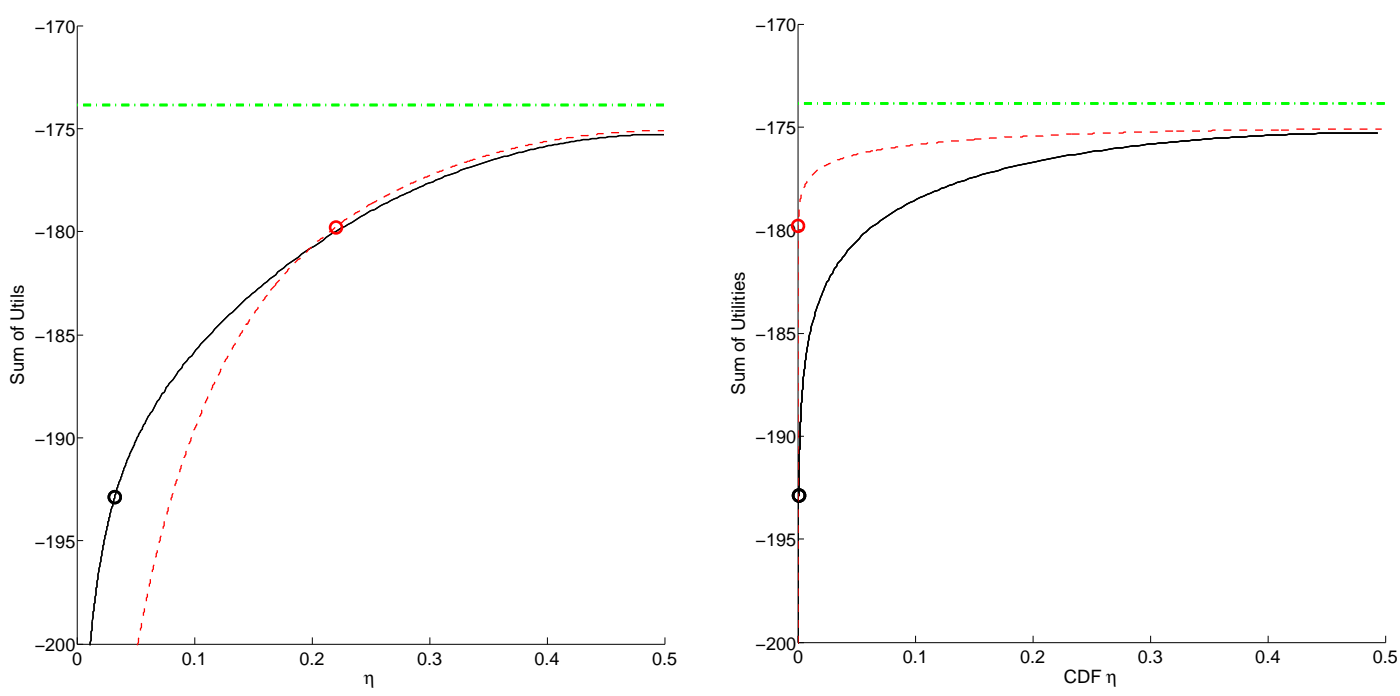

Figure 7: Panel A depicts the sum of both countries' welfares for different levels of wealth shares, $\eta$ for the case $s=1$. The first-best solution where the planner assigns equal Pareto weights to both type of agents is represented by the dashed-dotted green horizontal line. The outer increasing green dashed-dotted curve depicts the complete market solution for different initial $\eta$. The equilibrium outcome with an international debt market is given by the black solid curve and without an international debt market by the dashed red curve. Panel B represents the same graph but depicts on the x-axis the the cumulative density distribution of $\eta$ instead of $\eta$ itself. The circles mark the point $\eta^{a}$.

i.e., one that takes the relative frequency of different $\eta$-values into account. Note that any monotone transformation of $\eta$ would have been mathematically an equally good state variable to use, albeit more difficult to interpret economically. Taking instead of $\eta$ the cumulative (stationary) distribution function of $\eta$ is a particular attractive monotone transformation. The CDF of $\eta$ is uniformly distributed and hence one can easily integrate the areas between the curves. Figure 7 Panel A depicts the sum of both countries' welfare for different values of $\eta$ for the cases of (i) first best with equal Pareto weights $\lambda=\eta=1 / 2$, (ii) market equilibrium with open debt market and (iii) market equilibrium in which capital controls shut down the international debt market. Panel B depicts the sum of the value functions as a function of cumulative distribution function of $\eta$. Note that since the stationary distribution differs across these three cases, so does the transformation of $\eta$. In particular, for the first best case with constant $\eta=1 / 2$, the stationary distribution is step function with a step at $1 / 2$. The horizontal line depicts the first best sum of value functions of both agents for the case of $\eta=1 / 2$. Note that for other Pareto weights the first best horizontal line would be lower.

The differences between Figure 6 and Panel B of Figure 7 are striking. Figure 6 
suggests that capital controls are welfare reducing except for a small range of $\eta \mathrm{s}$ around 1/2. Panel A of Figure 7 points already out that for most values of $\eta$ capital controls are welfare enhancing. ${ }^{19}$ Panel A is still difficult to read since the stationary distribution of $\eta$ is more concentrated around $1 / 2$ for the case of capital control than for the case with open capital account. Panel B of Figure 7 takes the relative frequency of $\eta$ (based on the stationary distribution) into account. Panel B makes clear that this range of $\eta$-values for which capital controls are welfare improving is actually the relevant one. The economy is almost always within this range. In other words, Panel B of Figure 7 shows that initial $\eta$ values for which capital controls reduce welfare are rare events, indeed, they are so rare that they are unrecognizable in Panel B of Figure 7. Second, the values of $\eta$ for which the value frontier Figures 6 is inward bending and unanticipated debt relief program should be enacted are even further down in the extreme tails of the stationary distribution.

While for our parameter values capital controls are "almost always" utility value improving, this does not need to hold for all parameter values. As the fundamental exogenous risk $\sigma^{A}=\sigma^{B}$ rises the advantage of capital controls declines. Similarly, an increase in the substitutability of both output goods, i.e. in $s$, reduces the value of capital controls. Increasing $\underline{a}$ towards $\bar{a}$ has at least two implications. First, it lowers the price cap for the output good. Hence, the terms of trade hedge is reduced, reducing welfare. Second, the efficiency losses from producing the output good for which the output rate is only $\underline{a} k$ is smaller. This increases the welfare. As $\underline{a}$ approaches $\bar{a}$ the production efficiency loss vanishes, but so does also the terms of trade hedge. The overall welfare implications are not monotone in $\underline{a}$.

\section{Conclusion}

Magud, Reinhart and Rogoff (2011) complain about the lack of a unified theoretical framework to analyze the macroeconomic consequences of capital controls. This paper provides such a framework that is general enough that it can be calibrated and quantitative implications can be derived. It clearly identifies pecuniary externalities. The externality only arises in a multiple good setting and undermines the natural terms of trade hedge stressed in Cole and Obstfeld (1991). Open current accounts

\footnotetext{
${ }^{19}$ Capital controls increase the sum of both value functions for a large range of $\eta$. Capital controls are Pareto improving, i.e. $V^{A}(\eta)$ and $V^{B}(\eta)$ are higher with capital controls, only for a small range of $\eta$ around $1 / 2$. Outside this range of $\eta$ the value function of the poor country increases, while the value function of the rich country declines.
} 
that primarily lead to short-term debt financing also lead to a constrained inefficient outcome in terms of welfare and to a highly volatile market in terms of financial stability. The analysis shows that capital controls that shut down the international debt market can be welfare improving. Fine-tuned capital controls, e.g., by imposing taxes on debt capital flows, would extend the parameter space for which capital controls enhance overall welfare.

\section{References}

Acemoglu, Daron, and Jaume Ventura. 2002. "The World Income Distribution." Quarterly Journal of Economics, 117(2): 659-694.

Aoki, Kosuke, Gianluca Benigno, and Nobuhiro Kiyotaki. 2009. "Capital Flows and Asset Prices." In . , ed. Richard Clarida and Francesco Giavazzi, Chapter 4, 175-216. Chicago, IL:University of Chicago Press. http:/ /www.nber.org/chapters/c3006.

Backus, David K, and Mario J Crucini. 2000. "Oil prices and the terms of trade." Journal of International Economics, 50(1): 185-213.

Backus, David K., Patrick J. Kehoe, and Finn E. Kydland. 1994. "Dynamics of the Trade Balance and the Terms of Trade: The J-Curve?" The American Economic Review, 84(1): pp. 84-103.

Benigno, Pierpaolo. 2009. "Price Stability with Imperfect Financial Integration." Journal of Money, Credit and Banking, 41: 121-149.

Benigno, Pierpaolo, Chen Huigang, Christopher Otrok, and Alessandro Rebucci. 2014. "Optimal Capital Controls and Real Exchange Rate Policies: A Pecuniary Externality Perspective." Working paper.

Berka, Martin, Mario J Crucini, and Chih-Wei Wang. 2012. "International risk sharing and commodity prices." Canadian Journal of Economics/Revue canadienne d'économique, 45(2): 417-447.

Bernanke, Ben S., Mark Gertler, and Simon Gilchrist. 1999. "The Financial Accelerator in a Quantitative Business Cycle Framework." In Handbook of Macroeconomics. , ed. John B. Taylor and Michael Woodford. Elsevier. 
Bianchi, Javier. 2011. "Overborrowing and Systemic Externalities in the Business Cycle." American Economic Review, 101(7): 3400-3426.

Bianchi, Javier, and Enrique Mendoza. 2012. "Overborrowing, Financial Crises and 'Macro-prudential' Policy." Working Paper.

Bolton, Patrick, and David S. Scharfstein. 1990. "A Theory of Predation Based on Agency Problems in Financial Contracting." American Economic Review, 80(1): 93106.

Brunnermeier, Markus K., and Yuliy Sannikov. 2011. "The I Theory of Money." Working Paper.

Brunnermeier, Markus K., and Yuliy Sannikov. 2014. "A Macroeconomic Model with a Financial Sector." American Economic Review. forthcoming.

Caballero, Ricardo J., and Arvind Krishnamurthy. 2004. "Smoothing Sudden Stops." Journal of Economic Theory, 119(1): 104-127. Macroeconomics of Global Capital Market Imperfections.

Calvo, Guillermo A. 1998. "Capital Flows and Capital-Market Crises: The Simple Economics of Sudden Stops." Journal of Applied Economics, 0: 35-54.

Calvo, Guillermo A, Alejandro Izquierdo, and Ernesto Talvi. 2006. "Phoenix Miracles in Emerging Markets: Recovering Without Credit from Systemic Financial Crises." Inter-American Development Bank Research Department Working Paper 570.

Coeurdacier, Nicolas, Helene Rey, and Pablo Winant. 2013. "Financial Integration and Growth in a Risky World." Working Paper.

Cole, Harold L., and Maurice Obstfeld. 1991. "Commodity trade and international risk sharing : How much do financial markets matter?" Journal of Monetary Economics, 28(1): 3-24.

Committee on International Economic Policy and Reform. 2012. "Banks and Cross-Border Capital Flows: Policy Challenges and Regulatory Responses." Report, Brookings, Washington, D.C. http:/ / www.brookings.edu/research/reports/2012/09/ciepr-banks-capital-flows. 
Corsetti, Giancarlo, Luca Dedola, and Sylvain Leduc. 2008. "International Risk Sharing and the Transmission of Productivity Shocks." The Review of Economic Studies, 75(2): 443-473.

Costinot, Arnaud, Guido Lorenzoni, and Iván Werning. 2014. "A Theory of Capital Controls as Dynamic Terms-of-Trade Manipulation." Journal of Political Economy.

DeMarzo, Peter M., and Yuliy Sannikov. 2006. "Optimal Security Design and Dynamic Capital Structure in a Continuous-Time Agency Model." Journal of Finance, 61(6): 2681-2724.

Farhi, Emmanuel, and Iván Werning. 2012. "Dealing with the Trilemma: Optimal Capital Controls with Fixed Exchange Rates." Working Paper.

Farhi, Emmanuel, and Iván Werning. 2013. “Fiscal Unions.” Working Paper.

Fuller, Thomas. 2011. “Thailand Flooding Cripples Hard-Drive Suppliers." The New York Times.

Gabaix, Xavier, and Matteo Maggiori. 2014. "International Liquidity and Exchange Rate Dynamics." Working Paper.

Geanakoplos, John, and Heraklis M. Polemarchakis. 1986. “Existence, Regularity, and Constrained Suboptimality of Competitive Allocations when the Asset Market is Incomplete." In Uncertainty, Information and Communication: Essays in Honor of Kenneth J. Arrow. , ed. Walter P. Heller, Ross M. Starr and David A. Starrett. Cambridge University Press.

Hart, Oliver D. 1975. "On the optimality of equilibrium when the market structure is incomplete." Journal of Economic Theory, 11(3): 418-443.

Heathcote, Jonathan, and Fabrizio Perri. 2013. "The International Diversification Puzzle is Not as Bad as You Think." Journal of Political Economy. forthcoming.

Heathcote, Jonathan, and Fabrizio Perri. 2014. "On the Desirability of Capital Controls." Working Paper.

Helpman, Elhanan, and Assaf Razin. 1978. "A theory of international trade under uncertainty." University Library of Munich, Germany.

He, Zhiguo, and Peter Kondor. 2013. "Inefficient Investment Waves." Working Paper. 
Jeanne, Olivier, and Anton Korinek. 2011. "Managing Credit Booms and Busts: A Pigouvian Taxation Approach." Working Paper.

Jensen, Michael C., and William H. Meckling. 1976. "Theory of the firm: Managerial behavior, agency costs and ownership structure." Journal of Financial Economics, 3(4): $305-360$.

Keynes, John Maynard. 1929. "The German Transfer Problem." The Economic Journal, 39: pp. 1-7.

Kiyotaki, Nobuhiro, and John Moore. 1997. "Credit Cycles." Journal of Political Economy, 105(2): 211-248.

Korinek, Anton. 2011. "The New Economics of Prudential Capital Controls." IMF Economic Review, 59(3): 523-561.

Lewis, Karen K. 1999. "Trying to Explain Home Bias in Equities and Consumption." Journal of Economic Literature, 37(2): pp. 571-608.

Lorenzoni, Guido. 2014. "International Financial Crises." In Handbook of International Economics. Vol. 4, , ed. Gita Gopinath, Elhanan Helpman and Kenneth Rogoff. Elsevier.

Maggiori, Matteo. 2013. "Financial Intermediation, International Risk Sharing, and Reserve Currencies." Working Paper, NYU.

Magud, Nicolas E., Carmen M. Reinhart, and Kenneth S. Rogoff. 2011. "Capital Controls: Myth and Reality - A Portfolio Balance Approach." National Bureau of Economic Research Working Paper 16805.

Mendoza, Enrique G. 2010. "Sudden Stops, Financial Crises, and Leverage." American Economic Review, 100(4): 1941-1966.

Newbery, David M. G., and Joseph E. Stiglitz. 1984. "Pareto Inferior Trade." The Review of Economic Studies, 51(1): pp. 1-12.

Obstfeld, Maurice, and Alan M. Taylor. 2004. Global Capital Markets: Integration, Crisis, and Growth. Japan-U.S. Center Sanwa Monographs on International Financial Markets., Cambridge University Press. 
Obstfeld, Maurice, and Kenneth Rogoff. 1995. "Exchange Rate Dynamics Redux." Journal of Political Economy, 103(3): 624-660.

Ohlin, Bertil. 1929. “Mr. Keynes' views on the transfer problem. II. A rejoinder from professor Ohlin." The Economic Journal, 39: 400-4.

Ostry, Jonathan D., Atish R. Ghosh, Karl Habermeier, Marcos Chamon, Mahvash S. Qureshi, and Dennis B.S. Reinhardt. 2010. "Capital Inflows: The Role of Controls." International Monetary Fund. IMF Staff Position Note 10/04.

Pavlova, Anna, and Roberto Rigobon. 2007. "Asset Prices and Exchange Rates." The Review of Financial Studies, 20(4): pp. 1139-1181.

Phelan, Gregory. 2013. “Financial Intermediation, Leverage, and Macroeconomic Stability." Working Paper.

Samuelson, Paul A. 2004. "Where Ricardo and Mill Rebut and Confirm Arguments of Mainstream Economists Supporting Globalization." Journal of Economic Perspectives, 18(3): 135-146.

Schmitt-Grohé, Stephanie, and Martín Uribe. 2012. "Pegs and Pain." Working Paper.

Schmitt-Grohé, Stephanie, and Martín Uribe. 2013. "Downward Nominal Wage Rigidity, Currency Pegs, and Involuntary Unemployment." Working Paper.

Stiglitz, Joseph E. 1982. "The Inefficiency of the Stock Market Equilibrium." Review of Economic Studies, 49(2): 241-261. 


\section{Appendix}

\section{Proofs}

\section{A Proof of Proposition 1: First Best Analysis}

\section{A.1 Social Planner's Problem}

Under complete market and no frictions, agents would fully share the risks $d Z_{t}^{A}$ and $d Z_{t}^{B}$, and the equilibrium allocation solves a planner's problem, where welfare weights $\lambda$ and $1-\lambda$ depend on relative initial wealth of agents in country $A$ and $B$ :

$$
\begin{aligned}
\bar{V}\left(K_{0}\right)=\max _{C_{t}^{A}, C_{t}^{B}, \psi_{t, l t}} & \mathbb{E}_{0}\left[\int_{0}^{\infty} e^{-r t}\left[\lambda U\left(C_{t}^{A}\right)+(1-\lambda) U\left(C_{t}^{B}\right)\right] d t\right] \\
\text { s.t. } \quad Y_{t}^{a} & =\left(\bar{a} \psi_{t}^{A a}+\underline{a} \psi_{t}^{B a}\right) K_{t}, \\
Y_{t}^{b} & =\left(\bar{a} \psi_{t}^{B b}+\underline{a} \psi_{t}^{A b}\right) K_{t}, \\
Y_{t} & =\left[\frac{1}{2}\left(Y_{t}^{a}\right)^{\frac{s-1}{s}}+\frac{1}{2}\left(Y_{t}^{b}\right)^{\frac{s-1}{s}}\right]^{\frac{s}{s-1}}, \\
Y_{t} & =C_{t}^{A}+C_{t}^{B}+\iota_{t} K_{t}, \\
d K_{t} & =\left[\Phi\left(\iota_{t}\right)-\delta\right] K_{t} d t+\left(\psi_{t}^{A a}+\psi_{t}^{A b}\right) \sigma^{A} K_{t} d Z_{t}^{A}+\left(\psi_{t}^{B a}+\psi_{t}^{B b}\right) \sigma^{B} K_{t} d Z_{t}^{B}, \\
\psi_{t}^{I j} & \geq 0, \quad \psi_{t}^{A a}+\psi_{t}^{A b}+\psi_{t}^{B a}+\psi_{t}^{B b}=1
\end{aligned}
$$

The social planner will choose full specialization $\left(\psi_{t}^{A a}=\psi_{t}^{B b}=1 / 2\right)$. Since marginal cost of goods $a$ and $b$ are identical, marginal product of goods $a$ and $b$ in producing output-index $Y$ must be the same. Write out the marginal products to see that the social planner must also choose output equalization $\left(Y_{t}^{a}=Y_{t}^{b}\right)$. The aggregate production function will be $Y_{t}=\bar{a} K_{t} / 2$.

Denote the consumption intensities as $\zeta_{t}^{A} \equiv C_{t}^{A} / K_{t}$ and $\zeta_{t}^{B} \equiv C_{t}^{B} / K_{t}$. The social planner's problem above reduces to:

$$
\begin{aligned}
\bar{V}\left(K_{0}\right) & =\max _{\zeta_{t}^{A}, \zeta_{t}^{B} \geq 0} \mathbb{E}_{0}\left[\int_{0}^{\infty} e^{-r t}\left[\lambda U\left(\zeta_{t}^{A} K_{t}\right)+(1-\lambda) U\left(\zeta_{t}^{B} K_{t}\right)\right] d t\right] \\
\text { s.t. } & d K_{t} / K_{t}=\left[\Phi\left(\frac{\bar{a}}{2}-\zeta_{t}^{A}-\zeta_{t}^{B}\right)-\delta\right] d t+\frac{\sigma}{\sqrt{2}} \frac{d Z_{t}^{A}+d Z_{t}^{B}}{\sqrt{2}}
\end{aligned}
$$

Note that agents fully share the risks, the responses to Brownian shocks $d Z_{t}^{A}$ and 
$d Z_{t}^{B}$ are symmetric, we can aggregate them into a single standard Brownian shock $d Z_{t}=\left(d Z_{t}^{A}+d Z_{t}^{B}\right) / \sqrt{2}$. The HJB equation for the planner's problem is:

$$
\begin{aligned}
r \bar{V}(K) & =\max _{\zeta^{A}, \zeta^{B} \geq 0} \lambda U\left(\zeta^{A} K\right)+(1-\lambda) U\left(\zeta^{B} K\right) \\
& +\bar{V}_{K} K\left[\Phi\left(\frac{\bar{a}}{2}-\zeta^{A}-\zeta^{B}\right)-\delta\right]+\frac{1}{2} \bar{V}_{K K} K^{2} \frac{\sigma^{2}}{2}
\end{aligned}
$$

Next, we are solving for the equilibrium total consumption intensity $\zeta^{*}$. We first focus on the general CRRA case and then on the log-utility case.

CRRA Utility case. We conjecture that the solution of the value function takes on the following form: $\bar{V}(K)=\alpha \frac{K^{1-\gamma}}{1-\gamma}+h$ where $\alpha$ and $h$ are constants. Then $\bar{V}_{K} K=\alpha K^{1-\gamma}$ and $\bar{V}_{K K} K^{2}=-\gamma \alpha K^{1-\gamma}$. Plug into (31), the HJB under this conjecture is $(h=0)$ :

$r \alpha \frac{K^{1-\gamma}}{1-\gamma}=\max _{\zeta^{A}, \zeta^{B} \geq 0}\left\{\lambda \frac{\left(\zeta^{A}\right)^{1-\gamma}}{1-\gamma}+(1-\lambda) \frac{\left(\zeta^{B}\right)^{1-\gamma}}{1-\gamma}+\alpha\left[\Phi\left(\frac{\bar{a}}{2}-\zeta_{t}^{A}-\zeta_{t}^{B}\right)-\delta\right]-\frac{\gamma \alpha \sigma^{2}}{4}\right\} K^{1-\gamma}$

The terms in the bracket does not depend on $K$, which verifies the function form for $\bar{V}$. The first order conditions are:

$$
\begin{aligned}
(\lambda)^{\frac{-1}{\gamma}}\left(\zeta^{A}\right) & =\left[\alpha \Phi^{\prime}\left(\frac{\bar{a}}{2}-\zeta_{t}^{A}-\zeta_{t}^{B}\right)\right]^{\frac{-1}{\gamma}}, \\
(1-\lambda)^{\frac{-1}{\gamma}}\left(\zeta^{B}\right) & =\left[\alpha \Phi^{\prime}\left(\frac{\bar{a}}{2}-\zeta_{t}^{A}-\zeta_{t}^{B}\right)\right]^{\frac{-1}{\gamma}} .
\end{aligned}
$$

Let total consumption intensity be $\zeta^{*}=\zeta^{A}+\zeta^{B}$.

$$
\zeta^{A}=\frac{(\lambda)^{\frac{1}{\gamma}}}{(\lambda)^{\frac{1}{\gamma}}+(1-\lambda)^{\frac{1}{\gamma}}} \cdot \zeta^{*}, \quad \text { and } \quad \zeta^{B}=\frac{(1-\lambda)^{\frac{1}{\gamma}}}{(\lambda)^{\frac{1}{\gamma}}+(1-\lambda)^{\frac{1}{\gamma}}} \cdot \zeta^{*}
$$

The FOC becomes:

$$
\left(\zeta^{*}\right)^{-\gamma}=\left[(\lambda)^{\frac{1}{\gamma}}+(1-\lambda)^{\frac{1}{\gamma}}\right]^{-\gamma}\left[\alpha \Phi^{\prime}\left(\frac{\bar{a}}{2}-\zeta^{*}\right)\right]
$$

which involves $\alpha$ and $\zeta^{*}$. For given constant $\alpha$, LHS of the above equation is decreasing in the total consumption intensity $\zeta^{*}$ and RHS is increasing in $\zeta^{*}$.

To determine both $\alpha$ and $\zeta^{*}$ we need one more equation. Plug $\lambda\left(\zeta^{A}\right)^{-\gamma}=\alpha \Phi^{\prime}$ and 
$(1-\lambda)\left(\zeta^{B}\right)^{-\gamma}=\alpha \Phi^{\prime}$ into the HJB equation:

$$
\frac{r \alpha}{1-\gamma}=\frac{\zeta^{*}}{1-\gamma} \alpha \Phi^{\prime}\left(\frac{\bar{a}}{2}-\zeta^{*}\right)+A\left[\Phi\left(\frac{\bar{a}}{2}-\zeta^{*}\right)-\delta\right]-\frac{\gamma \sigma^{2} \alpha}{4}
$$

The $\alpha^{\prime}$ s cancel out and the above HJB becomes a single variate equation in $\zeta^{*}$ :

$$
\frac{r}{1-\gamma}=\frac{\zeta^{*}}{1-\gamma} \Phi^{\prime}\left(\frac{\bar{a}}{2}-\zeta^{*}\right)+\left[\Phi\left(\frac{\bar{a}}{2}-\zeta^{*}\right)-\delta\right]-\frac{\gamma \sigma^{2}}{4}
$$

Importantly, the total consumption intensity $\zeta^{*}$ does not depend on $K_{t}$. For appropriate functional form and parameters we can solve out $\zeta^{*}$, the optimal total consumption intensity, using above version of HJB.

Log Utility Case. For the case of log utility we conjecture that the value function takes on the following form $\bar{V}(K)=\alpha \log (K)+h$ where $\alpha$ and $h$ are constants. Then $\bar{V}_{K} K=\alpha$ and $\bar{V}_{K K} K^{2}=-\alpha$. First order conditions for the HJB equation 31 are:

$$
\begin{aligned}
\frac{\lambda}{\zeta^{A}} & =\alpha \Phi^{\prime}\left(\frac{\bar{a}}{2}-\zeta_{t}^{A}-\zeta_{t}^{B}\right), \\
\frac{1-\lambda}{\zeta^{B}} & =\alpha \Phi^{\prime}\left(\frac{\bar{a}}{2}-\zeta_{t}^{A}-\zeta_{t}^{B}\right) .
\end{aligned}
$$

Under log utility, consumption shares are proportional to the welfare weights $\left(\frac{\zeta^{A}}{\zeta^{B}}=\frac{\lambda}{1-\lambda}\right)$. Furthermore, since the $\zeta^{\prime}$ s do not depend on $K$ (scale invariance), coefficient $\alpha$ equals $r^{-1}$ and we verify the function form assumed on $\bar{V}$.

Let $\zeta \equiv \zeta^{A}+\zeta^{B}$, the optimal consumption intensity $\zeta^{*}$ is then pinned down by:

$$
\left(\zeta^{*}\right)^{-1}=\frac{1}{r} \Phi^{\prime}\left(\frac{\bar{a}}{2}-\zeta^{*}\right)
$$

where the LHS is marginal utility in consumption intensities and the RHS is the marginal efficiency of capital investment times the marginal value of capital (in rates). Importantly, $\zeta^{*}$ does not depend on $K_{t}$. The LHS is decreasing in $\zeta^{*}$ from $+\infty$ to 0 and the RHS is increasing in $\zeta^{*}$ from $\Phi^{\prime}\left(\frac{a}{2}\right)>0$ to $\Phi^{\prime}(-\infty)$. There exists a unique $\zeta^{*}$ that solves the planner's problem. The individual consumption intensities are $\zeta^{A *}=\lambda \zeta^{*}$ and $\zeta_{B *}=(1-\lambda) \zeta^{*}$. The value function $\bar{V}$ for the social planner's problem is:

$$
\bar{V}(K)=\frac{1}{r}\left[\log \left(\zeta^{*} K\right)+\lambda \log (\lambda)+(1-\lambda) \log (1-\lambda)\right]+\frac{1}{r^{2}}\left[\Phi\left(\frac{\bar{a}}{2}-\zeta^{*}\right)-\delta\right]-\frac{\sigma^{2}}{4 r^{2}} .
$$




\section{A.2 Decentralization: Representative Agent Economy}

The original planner's problem is equivalent to a representative agent with utility function $\tilde{U}$ defined by

$$
\tilde{U}(C)=\tilde{U}(\zeta K) \equiv \max _{\zeta^{A}+\zeta^{B} \leq \zeta} \lambda U\left(\zeta^{A} K\right)+(1-\lambda) U\left(\zeta^{B} K\right)
$$

facing the following problem:

$$
\begin{aligned}
\tilde{V}^{R}\left(K_{0}\right) & =\max _{\zeta \geq 0} \mathbb{E}_{0}\left[\int_{0}^{\infty} e^{-r t}\left[\tilde{U}\left(\zeta_{t} K_{t}\right)\right] d t\right] \\
\text { s.t. } \quad d K_{t} & =\left[\Phi\left(\frac{\bar{a}}{2}-\zeta_{t}\right)-\delta\right] K_{t} d t+\frac{\sigma}{\sqrt{2}} K_{t} d Z_{t}
\end{aligned}
$$

To decentralize a planner's problem we need to solve for the prices consistent with the planner's solution. In the planner's problem consumption is a constant fraction of total capital, so $d C_{t} / C_{t}$ follows the same stochastic process as $d K_{t} / K_{t}$. Using the asset-pricing condition ( Equation (11) ) we can compute the risk-free interest rate $r^{F}$

$$
\frac{d r^{F}}{d t}=r+\gamma\left[\Phi\left(\frac{\bar{a}}{2}-\zeta^{*}\right)-\delta\right]-\frac{\gamma(\gamma+1) \sigma^{2}}{4}
$$

The inverse of marginal rate of transformation equals capital prices hence

$$
q=\left[\Phi^{\prime}\left(\frac{\bar{a}}{2}-\zeta^{*}\right)\right]^{-1}
$$

Observe that $q$ is constant over time. Then we can use the Equation (12) to price the return on capital and get capital prices.

$$
\frac{d r^{F}}{d t}=\underbrace{\frac{\zeta^{*}}{q}+\left[\Phi\left(\frac{\bar{a}}{2}-\zeta^{*}\right)-\delta\right]}_{\text {return on capital }}+\frac{\sigma}{\sqrt{2}} \cdot\left(-\frac{\gamma \sigma}{\sqrt{2}}\right) .
$$




\section{B Proof of Proposition 2}

Proof. Recall that the return processes follow

$$
\begin{aligned}
& d r_{t}^{A a}=\left(\frac{\bar{a} P_{t}^{a}-\iota_{t}}{q_{t}}+\mu_{t}^{q}+\Phi\left(\iota_{t}\right)-\delta+\sigma^{A} \sigma_{t}^{q A}\right) d t+\left(\sigma^{A}+\sigma_{t}^{q A}\right) d Z_{t}^{A}+\sigma_{t}^{q B} d Z_{t}^{B} \\
& d r_{t}^{A b}=\left(\frac{\underline{a} P_{t}^{b}-\iota_{t}}{q_{t}}+\mu_{t}^{q}+\Phi\left(\iota_{t}\right)-\delta+\sigma^{A} \sigma_{t}^{q A}\right) d t+\left(\sigma^{A}+\sigma_{t}^{q A}\right) d Z_{t}^{A}+\sigma_{t}^{q B} d Z_{t}^{B} \\
& d r_{t}^{B a}=\left(\frac{a P_{t}^{a}-\iota_{t}}{q_{t}}+\mu_{t}^{q}+\Phi\left(\iota_{t}\right)-\delta+\sigma^{B} \sigma_{t}^{q B}\right) d t+\sigma_{t}^{q A} d Z_{t}^{A}+\left(\sigma^{B}+\sigma_{t}^{q B}\right) d Z_{t}^{B} \\
& d r_{t}^{B b}=\left(\frac{\bar{a} P_{t}^{b}-\iota_{t}}{q_{t}}+\mu_{t}^{q}+\Phi\left(\iota_{t}\right)-\delta+\sigma^{B} \sigma_{t}^{q B}\right) d t+\sigma_{t}^{q A} d Z_{t}^{A}+\left(\sigma^{B}+\sigma_{t}^{q B}\right) d Z_{t}^{B}
\end{aligned}
$$

Using equations (10) to (13), the risk-free rate is given by

$$
\frac{d r^{F}}{d t}=r+\gamma \mu_{t}^{C}-\frac{\gamma(\gamma+1)}{2}\left(\left(\sigma_{t}^{C^{A} A}\right)^{2}+\left(\sigma_{t}^{C^{A} B}\right)^{2}\right)
$$

whereas the excess returns can be expressed as

$$
\begin{aligned}
& \frac{\bar{a} P_{t}^{a}-\iota_{t}}{q_{t}}+\mu_{t}^{q}+\Phi\left(\iota_{t}\right)-\delta+\sigma^{A} \sigma_{t}^{q A}-\frac{d r^{F}}{d t}=\gamma\left(\sigma^{A}+\sigma^{q A}\right) \sigma_{t}^{C^{A} A}+\gamma \sigma_{t}^{q B} \sigma_{t}^{C^{A} B} \\
& \frac{a P_{t}^{b}-\iota_{t}}{q_{t}}+\mu_{t}^{q}+\Phi\left(\iota_{t}\right)-\delta+\sigma^{A} \sigma_{t}^{q A}-\frac{d r^{F}}{d t} \leq \gamma\left(\sigma^{A}+\sigma^{q A}\right) \sigma_{t}^{C^{A} A}+\gamma \sigma_{t}^{q B} \sigma_{t}^{C^{A} B} \\
& \frac{a P_{t}^{a}-\iota_{t}}{q_{t}}+\mu_{t}^{q}+\Phi\left(\iota_{t}\right)-\delta+\sigma^{B} \sigma_{t}^{q B}-\frac{d r^{F}}{d t} \leq \gamma \sigma_{t}^{q A} \sigma_{t}^{C^{B} A}+\gamma\left(\sigma^{B}+\sigma_{t}^{q B}\right) \sigma_{t}^{C^{B} B} \\
& \frac{\bar{a} P_{t}^{b}-\iota_{t}}{q_{t}}+\mu_{t}^{q}+\Phi\left(\iota_{t}\right)-\delta+\sigma^{B} \sigma_{t}^{q B}-\frac{d r^{F}}{d t}=\gamma \sigma_{t}^{q A} \sigma_{t}^{C^{B} A}+\gamma\left(\sigma^{B}+\sigma_{t}^{q B}\right) \sigma_{t}^{C^{B} B}
\end{aligned}
$$

From these excess returns we can derive the following equilibrium asset-pricing conditions

$$
\begin{aligned}
\frac{\bar{a}\left(P_{t}^{a}-P_{t}^{b}\right)}{q_{t}}+\sigma^{A} \sigma_{t}^{q A}-\sigma^{B} \sigma_{t}^{q B} & =\gamma\left(\sigma^{A}+\sigma_{t}^{q A}\right) \sigma_{t}^{C^{A} A}+\gamma \sigma_{t}^{q B} \sigma_{t}^{C^{A} B}-\gamma \sigma_{t}^{q A} \sigma_{t}^{C^{B} A}-\gamma\left(\sigma^{B}+\sigma_{t}^{q B}\right) \sigma_{t}^{C^{B} B} \\
\underline{a} P_{t}^{a} & \leq \bar{a} P_{t}^{b} \quad \text { with equality if } \psi_{t}^{B a}>0
\end{aligned}
$$

With portfolio weights $\psi_{t}^{A a} / \eta_{t}$ and $\psi_{t}^{A b} / \eta_{t}$ on the two technologies, the law of 
motion of the net worth of agents $A$ is

$$
\begin{aligned}
\frac{d N_{t}}{N_{t}} & =\underbrace{\frac{\psi_{t}^{A a}+\psi_{t}^{A b}}{\eta_{t}} \gamma\left[\left(\sigma^{A}+\sigma_{t}^{q A}\right) \sigma_{t}^{C^{A} A}+\sigma_{t}^{q B} \sigma_{t}^{C A} B\right] d t}_{\sigma_{t}^{N A}}+\frac{d r^{F}}{d t} d t-\frac{C_{t}^{A}}{N_{t}} d t \\
& +\underbrace{\frac{\psi_{t}^{A a}+\psi_{t}^{A b}}{\eta_{t}}\left(\sigma^{A}+\sigma_{t}^{q A}\right)}_{\sigma_{t}^{N B}} d Z_{t}^{A}+\underbrace{\frac{\psi_{t}^{A a}+\psi_{t}^{A b}}{\eta_{t}} \sigma_{t}^{q B}}_{t} d Z_{t}^{B} \\
& =\gamma\left[\sigma_{t}^{N A} \sigma_{t}^{C^{A} A}+\sigma_{t}^{N B} \sigma_{t}^{C^{A} B}\right] d t+\frac{d r^{F}}{d t} d t-\frac{C_{t}^{A}}{N_{t}} d t+\sigma_{t}^{N A} d Z_{t}^{A}+\sigma_{t}^{N B} d Z_{t}^{B}
\end{aligned}
$$

The law of motion of aggregate wealth can be found by computing the return on the aggregate portfolio of capital, and subtracting the dividend yield, i.e.

$$
\begin{aligned}
\frac{d\left(q_{t} K_{t}\right)}{q_{t} K_{t}} & =\left(\psi_{t}^{A a}+\psi_{t}^{A b}\right) \gamma\left[\left(\sigma^{A}+\sigma_{t}^{q A}\right) \sigma_{t}^{C^{A} A}+\sigma_{t}^{q B} \sigma_{t}^{C^{A} B}\right] d t \\
& +\left(\psi_{t}^{B a}+\psi_{t}^{B b}\right) \gamma\left[\sigma_{t}^{q A} \sigma_{t}^{C^{B} A}+\left(\sigma^{B}+\sigma_{t}^{q B}\right) \sigma_{t}^{C^{B} B}\right] d t+\frac{d r^{F}}{d t} d t-\frac{Y_{t}-\iota_{t} K_{t}}{q_{t} K_{t}} d t \\
& +\left(\psi_{t}^{A a}+\psi_{t}^{A b}\right)\left[\left(\sigma^{A}+\sigma^{q A}\right) d Z_{t}^{A}+\sigma_{t}^{q B} d Z_{t}^{B}\right] \\
& +\left(\psi_{t}^{B a}+\psi_{t}^{B b}\right)\left[\sigma^{q A} d Z_{t}^{A}+\left(\sigma^{B}+\sigma_{t}^{q B}\right) d Z_{t}^{B}\right]
\end{aligned}
$$

It may appear strange that we derived this expression by subtracting dividend yield from the return on the world portfolio, instead of by multiplying the laws of motion of $q$ and $K$. The benefit of this approach is that it allows us to express the law of motion of $\eta_{t}$ without using $\mu_{t}^{q}$ and $d r^{F} / d t$. Thus, the law of motion of $\eta$ that we obtain in the end can be computed purely from the first derivatives of $q, C^{A}$ and $C^{B}$ (without second derivatives). 
Using Ito's lemma,

$$
\begin{aligned}
& \frac{d \eta_{t}}{\eta_{t}}=\frac{1-\eta_{t}}{\eta_{t}}\left(\psi_{t}^{A a}+\psi_{t}^{A b}\right) \gamma\left[\left(\sigma^{A}+\sigma_{t}^{q A}\right) \sigma_{t}^{C^{A} A}+\sigma_{t}^{q B} \sigma_{t}^{C^{A} B}\right] d t \\
& -\left(\psi_{t}^{B a}+\psi_{t}^{B b}\right) \gamma\left[\sigma_{t}^{q A} \sigma_{t}^{C^{B} A}+\left(\sigma^{B}+\sigma_{t}^{q B}\right) \sigma_{t}^{C^{B} B}\right] d t-\frac{C_{t}^{A}}{N_{t}} d t+\frac{Y_{t}-\iota_{t} K_{t}}{q_{t} K_{t}} d t \\
& +\underbrace{\left[\frac{1-\eta_{t}}{\eta_{t}}\left(\psi_{t}^{A a}+\psi_{t}^{A b}\right)\left(\sigma^{A}+\sigma_{t}^{q A}\right)-\left(\psi_{t}^{B a}+\psi_{t}^{B b}\right) \sigma_{t}^{q A}\right]}_{\sigma_{t}^{\eta A}} d Z_{t}^{A} \\
& +\underbrace{\left[\frac{1-\eta_{t}}{\eta_{t}}\left(\psi_{t}^{A a}+\psi_{t}^{A b}\right) \sigma_{t}^{q B}-\left(\psi_{t}^{B a}+\psi_{t}^{B b}\right)\left(\sigma^{B}+\sigma_{t}^{q B}\right)\right]}_{\sigma_{t}^{\eta B}} d Z_{t}^{B} \\
& -\left[\left(\psi_{t}^{A a}+\psi_{t}^{A b}\right)\left(\sigma^{A}+\sigma^{q A}\right)+\left(\psi_{t}^{B a}+\psi_{t}^{B b}\right) \sigma_{t}^{q A}\right] \frac{\psi_{t}^{A a}+\psi_{t}^{A b}}{\eta_{t}}\left(\sigma^{A}+\sigma^{q A}\right) d t \\
& -\left[\left(\psi_{t}^{A a}+\psi_{t}^{A b}\right) \sigma_{t}^{q B}+\left(\psi_{t}^{B a}+\psi_{t}^{B b}\right)\left(\sigma^{B}+\sigma_{t}^{q B}\right)\right] \frac{\psi_{t}^{A a}+\psi_{t}^{A b}}{\eta_{t}} \sigma^{q B} d t \\
& +\left[\left(\psi_{t}^{A a}+\psi_{t}^{A b}\right)\left(\sigma^{A}+\sigma^{q A}\right)+\left(\psi_{t}^{B a}+\psi_{t}^{B b}\right) \sigma_{t}^{q A}\right]^{2} d t \\
& +\left[\left(\psi_{t}^{A a}+\psi_{t}^{A b}\right) \sigma_{t}^{q B}+\left(\psi_{t}^{B a}+\psi_{t}^{B b}\right)\left(\sigma^{B}+\sigma_{t}^{q B}\right)\right]^{2} d t
\end{aligned}
$$

and (16) follows if we set $\psi_{t}^{A b}=0$ and simplify.

\section{Proof of Proposition 4}

Proof. We only need to derive the law of motion of $\eta_{t}$. The net worth of agents $\mathrm{A}$ on $\left[0, \eta^{b}\right)$ follows

$$
\frac{d N_{t}^{A}}{N_{t}^{A}}=\underbrace{\left(\frac{\bar{a} P_{t}^{a}-\iota_{t}}{q_{t}}+\mu_{t}^{q}+\Phi\left(\iota_{t}\right)-\delta+\sigma^{A} \sigma_{t}^{q A}\right) d t+\left(\sigma^{A}+\sigma_{t}^{q A}\right) d Z_{t}^{A}+\sigma_{t}^{q B} d Z_{t}^{B}}_{d r_{t}^{A a}}-r d t
$$

The aggregate net worth of all agents follows

$$
\begin{aligned}
\frac{d\left(q_{t} K_{t}\right)}{q_{t} K_{t}} & =\left(\mu_{t}^{q}+\Phi\left(\iota_{t}\right)-\delta+\eta_{t} \sigma^{A} \sigma^{q A}+\left(1-\eta_{t}\right) \sigma^{B} \sigma^{q B}\right) d t \\
& +\left(\eta_{t} \sigma^{A}+\sigma_{t}^{q A}\right) d Z_{t}^{A}+\left(\left(1-\eta_{t}\right) \sigma^{B}+\sigma_{t}^{q B}\right) d Z_{t}^{B}
\end{aligned}
$$


Therefore, using Ito's lemma, the volatility of $\eta$ is given by $\sigma_{t}^{\eta A}=\left(1-\eta_{t}\right) \sigma^{A}, \sigma_{t}^{\eta B}=$ $-\left(1-\eta_{t}\right) \sigma^{B}$. Likewise, the drift of $\eta_{t}$ is

$$
\frac{\bar{a} P_{t}^{a}-\iota_{t}}{q_{t}}-r-\left(1-\eta_{t}\right)\left[\sigma^{A} \eta_{t} \sigma^{A}-\sigma^{B}\left(1-\eta_{t}\right) \sigma^{B}\right]
$$

which leads to (29) after simplifications.

\section{Proof of Proposition 5}

The value for the first best is simple noting that with log utility agents consume a fixed fraction of their wealth at any time. To solve the value function in competitive equilibrium, we adopt the following steps.

The value function of a representative agent in country A takes the form $V\left(N_{t}, \eta_{t}\right)=$ $\log \left(\eta_{t}\right) / r+\log \left(K_{t}\right) / r+H\left(\eta_{t}\right)$. The HJB equation is

$r\left(\frac{\log \eta_{t}}{r}+\frac{\log K_{t}}{r}+H\left(\eta_{t}\right)\right)=\log \left(C_{t}\right)+\frac{1}{r} \mathbb{E}\left[\frac{d \log \left(\eta_{t}\right)}{d t}\right]+\frac{1}{r} \mathbb{E}\left[\frac{d \log \left(K_{t}\right)}{d t}\right]+\mathbb{E}\left[\frac{d H\left(\eta_{t}\right)}{d t}\right]$

Using Ito's lemma,

$$
\begin{gathered}
\log \left(\eta_{t}\right)+\log \left(K_{t}\right)+r H\left(\eta_{t}\right)=\log \left(r \eta_{t} q_{t} K_{t}\right)+\frac{\mu_{t}^{\eta}}{r}-\frac{\left(\sigma_{t}^{\eta A}\right)^{2}+\left(\sigma_{t}^{\eta B}\right)^{2}}{2 r}+ \\
\frac{\mu_{t}^{K}}{r}-\frac{\left(\sigma_{t}^{K A}\right)^{2}+\left(\sigma_{t}^{K B}\right)^{2}}{2 r}+\mu_{t}^{\eta} \eta H^{\prime}(\eta)+\frac{\left(\sigma_{t}^{\eta A}\right)^{2}+\left(\sigma_{t}^{\eta B}\right)^{2}}{2} \eta^{2} H^{\prime \prime}(\eta)
\end{gathered}
$$

We can simplify the equation by first eliminating $\log \left(\eta_{t}\right)+\log \left(K_{t}\right)$ on both sides. Second, let us substitute

$$
\mu_{t}^{K}=\Phi\left(\iota_{t}\right)-\delta, \quad \sigma_{t}^{K A}=\left(\psi_{t}^{A a}+\psi_{t}^{A b}\right) \sigma^{A} \quad \text { and } \quad \sigma_{t}^{K B}=\left(\psi_{t}^{B a}+\psi_{t}^{B b}\right) \sigma^{B} .
$$

Then we obtain

$$
\begin{gathered}
r H(\eta)=\log (r q(\eta))+\frac{\mu_{t}^{\eta}}{r}-\frac{\left(\sigma_{t}^{\eta A}\right)^{2}+\left(\sigma_{t}^{\eta B}\right)^{2}}{2 r}+\frac{\Phi\left(\iota_{t}\right)-\delta}{r}- \\
\frac{\left(\psi^{A a}+\psi^{A b}\right)^{2}\left(\sigma^{A}\right)^{2}+\left(\psi^{B a}+\psi^{B b}\right)^{2}\left(\sigma^{B}\right)^{2}}{2 r}+\mu_{t}^{\eta} \eta H^{\prime}(\eta)+\frac{\left(\sigma_{t}^{\eta A}\right)^{2}+\left(\sigma_{t}^{\eta B}\right)^{2}}{2} \eta^{2} H^{\prime \prime}(\eta)
\end{gathered}
$$

The welfare of agents in country B satisfies a symmetric equation. 


\section{Algorithm}

\section{A Equilibrium}

This appendix describes the algorithm used to compute the numerical examples in this paper. The key equilibrium objects are $q(\eta), \psi^{A a}(\eta), \psi^{A b}(\eta), \psi^{B a}(\eta)$ and $\psi^{B b}(\eta)$. Once we have these functions we can solve for the drifts and volatilities, outputs of goods $a$ and $b$, aggregate output and the goods prices.

We compute the dynamics of $q(\eta), \psi^{A a}(\eta), \psi^{A b}(\eta), \psi^{B a}(\eta)$ and $\psi^{B b}(\eta)$ only on the domain $\eta \in[0,0.5]$. For $\eta \in(0.5,1]$ the solution is symmetric. We also determine the endogenous threshold $\eta^{a}$ (the threshold $\eta^{b}$ is determined symmetrically). Within the domain $\eta \in[0,0.5]$ agents in the poorer country $A$ do not produce good $b$, so we set $\psi^{A b}(\eta)=0$. Since $\psi^{B b}(\eta)=1-\psi^{A a}(\eta)-\psi^{B a}(\eta)$ by capital market clearing, we can restrict the algorithm to solving for the two capital shares $\psi^{A a}(\eta)$ and $\psi^{B a}(\eta)$, along with the capital price $q(\eta)$. The algorithm solves a system of implicit differential equations in three equilibrium conditions: goods market clearing, debt market clearing, and country B's portfolio decision. The algorithm is as follows:

1. Consider first the region $\left[0, \eta^{a}\right)$, where $B$ produces good $a$. First, we need to compute initial conditions. We calculate the level $\psi^{A a}(0)$ analytically. Then, we use the Matlab function decic to compute initial conditions $\psi^{A a}(0), \psi^{B a}(0), q(0)$ and $\left(\psi^{A a}\right)^{\prime}(0),\left(\psi^{B a}\right)^{\prime}(0), q^{\prime}(0)$ that are consistent with the system of implicit differential equations, holding $\psi^{A a}(0)$ fixed.

2. Given the initial conditions, we use Matlab's implicit ODE solver, ode15i, to solve for $q(\eta), \psi^{A a}(\eta), \psi^{B a}(\eta)$ using the three equilibrium conditions. We then determine the endogenous threshold $\eta^{a}$ as the $\eta$ where $\psi^{B a}(\eta)$ reaches zero.

3. Next consider the middle region $\left[\eta^{a}, 0.5\right]$. Forcing $q(\cdot)$ to be continuous in $\eta$ and setting $\psi^{B a}\left(\eta^{a}\right)=0$, use the decic function to determine consistent initial conditions at $\eta^{a}$.

4. In the region $\left[\eta^{a}, 0.5\right]$, use these initial conditions and proceed as in 2. to solve the appropriate equilibrium conditions to obtain the functions $q(\eta), \psi^{A a}(\eta), \psi^{B a}(\eta)$, $\eta \in\left[\eta^{a}, 0.5\right]$. Specifically, in this region $B$ does not hold capital to produce $a$.

5. Once we have $q(\eta), \psi^{A a}(\eta), \psi^{B a}(\eta)$ and their derivatives, use the appropriate equations in the text to solve for the drifts and volatilities of $d \eta, d q, d C^{I}$, the outputs, $Y^{a}, Y^{b}, Y$, and the prices $P^{a}, P^{b}$ for each value of $\eta \in[0,0.5]$. 
6. Finally, we compute the stationary distribution of $\eta$ from the Kolmogorov forward equation using the same algorithm as in Brunnermeier and Sannikov (2014).

\section{B Welfare}

Here we outline the procedure used to solve for $H(\eta)$ from the value function used to calculate welfare under the closed and open capital account for debt.

1. Given the computed equilibrium we use the explicit ODE solver ode45 to solve the functions $H^{A}(\eta), H^{B}(\eta)$ on $\eta \in[0,0.5]$, together with an auxiliary function $H(\eta)$ which is a solution to the (common) homogeneous part of the ODEs of $H^{A}(\eta)$ and $H^{B}(\eta)$.

2. For $\eta \in(0.5,1]$, by symmetry we have $H^{A}(\eta)=H^{B}(1-\eta)$ and $H^{B}(\eta)=H^{A}(1-$ $\eta)$. Moreover we have $H^{A}(0.5)=H^{B}(0.5)$ and $\left(H^{A}\right)^{\prime}(0.5)=-\left(H^{B}\right)^{\prime}(0.5)$ as the boundary conditions.

3. We solve $H^{A}(0), H^{B}(0), H(0)$ analytically, set the initial first order derivatives to be $\left(H^{A}\right)^{\prime}(0)=0,\left(H^{B}\right)^{\prime}(0)=0$, and normalize $H^{\prime}(0)=1$.

4. We plug the initial conditions into ode 45 to solve for the complementary function $H(\eta)$ and two particular integrals $\tilde{H}^{A}(\eta), \tilde{H}^{B}(\eta)$.

5. Note that the general solutions to the ODEs are of the form of $\tilde{H}^{I}(\eta)+c^{I} H(\eta)$ with constants $c^{I}$ and $I \in\{A, B\}$. We use the boundary conditions at $\eta=0.5$ to pin down $c^{A}, c^{B}$ and obtain two particular solutions. 